\title{
Greenhouse gas penalty and incentive policies for a joint economic lot size model with industrial and transport emissions
}

\author{
Ivan Darma Wangsa ${ }^{a^{*}}$
}

${ }^{a}$ Department of Industrial and Systems Engineering, Chung Yuan Christian University, Chungli 32023, Taiwan, R.O.C.

\begin{tabular}{l}
\hline C H R O N I C L E \\
\hline Article history: \\
Received October 272016 \\
Received in Revised Format \\
December 222016 \\
Accepted March 12017 \\
Available online \\
March 22017 \\
\hline Keywords: \\
A joint economic lot size model \\
Greenhouse gas emission \\
Direct and indirect emissions \\
Penalty and incentive policies and \\
stochastic demand
\end{tabular}

Article history:

Received October 272016

December 222016

Accepted March 12017

Available online

Direct and indirect emissions

stochastic demand \begin{abstract}
A B S T R A C T
This paper presents a joint economic lot size model for a single manufacturer-a single buyer. The purposed model involves the greenhouse gas emission from industrial and transport sectors. We divide the emission into two types, namely the direct and indirect emissions. In this paper, we consider the Government's penalty and incentive policies to reduce the emission. We assume that the demand of the buyer is normally distributed and partially backordered. The objective is to minimize joint total cost incurred by a single manufacturer-a single buyer and involves the transportation costs of the freight forwarder. Transportation costs are the function of shipping weight, distance, fuel price and consumption with two transportation modes: truckload and lessthan-truckload shipments. Finally, an algorithm procedure is proposed to determine the optimal order quantity, safety factor, actual shipping weight, total emission and frequency of deliveries. Numerical examples and analyses are given to illustrate the results.
\end{abstract}

\section{Introduction}

Global warming as an indicator of climate change occurs as a result of increasing greenhouse gasses (GHGs). Human activities produce the increasingly large amount of GHGs, particularly CO2, which is accumulated in the atmosphere. GHG reduction, an especially $\mathrm{CO}_{2}$ emission reduction is the only way for human survival in facing global warming. The Kyoto Protocol is issued and signed in 1998 by the members of the United Nations (UN) and the European Union (EU), aiming for all participating countries to be committed to reducing the GHG emission amount by 5\% to the 1990 level. As a result, many countries have ratified the protocol and have enacted regulations to reduce carbon emission. Policymakers designed regulations such as carbon caps, carbon tax, carbon cap and trade or carbon offset (Benjaafar et al., 2012). An example of the emission standards for diesel engines implemented by EU is that it will be given penalties for vehicles that do not meet minimum standards (Piecyk et al., 2007). Carbon emission can be incurred at various activities.

* Corresponding author Tel.: $\quad+62-81350888343$

E-mail: ivan darma@yahoo.com (I. D. Wangsa)

(C) 2017 Growing Science Ltd. All rights reserved. doi: $10.5267 /$ j.ijiec.2017.3.003 
Freight transportation and manufacturing industry are viewed as leading sectors in economic development. These sectors are the major factors in emission sources and energy consumption. For instance, GHG emissions from transport and industry in the US accounted for $26 \%$ and $21 \%$ of the total in 2014, respectively (www.epa.gov). GHG emissions from transport sector come from burning fossil fuels for trucks, cars, ships, trains and planes. Meanwhile, GHG emissions from industry come from fossil fuels for energy to produce products from raw materials. The energy consumption of transport and industry sectors is affected by direct and indirect emissions. Direct emissions are the emissions produced from the activities controlled by the companies that are directly related to GHG emissions, such as controlled boilers (generators), furnaces, vehicles, production process and equipment (forklifts) etc. Indirect emissions are the emissions resulted from company activities but are produced by the sources beyond the company. Indirect emission is associated with the amount of energy used and the utility supplying it such as purchased electricity, heat, steam, and cooling. The classification of emissions in this article is shown in Fig. 1.

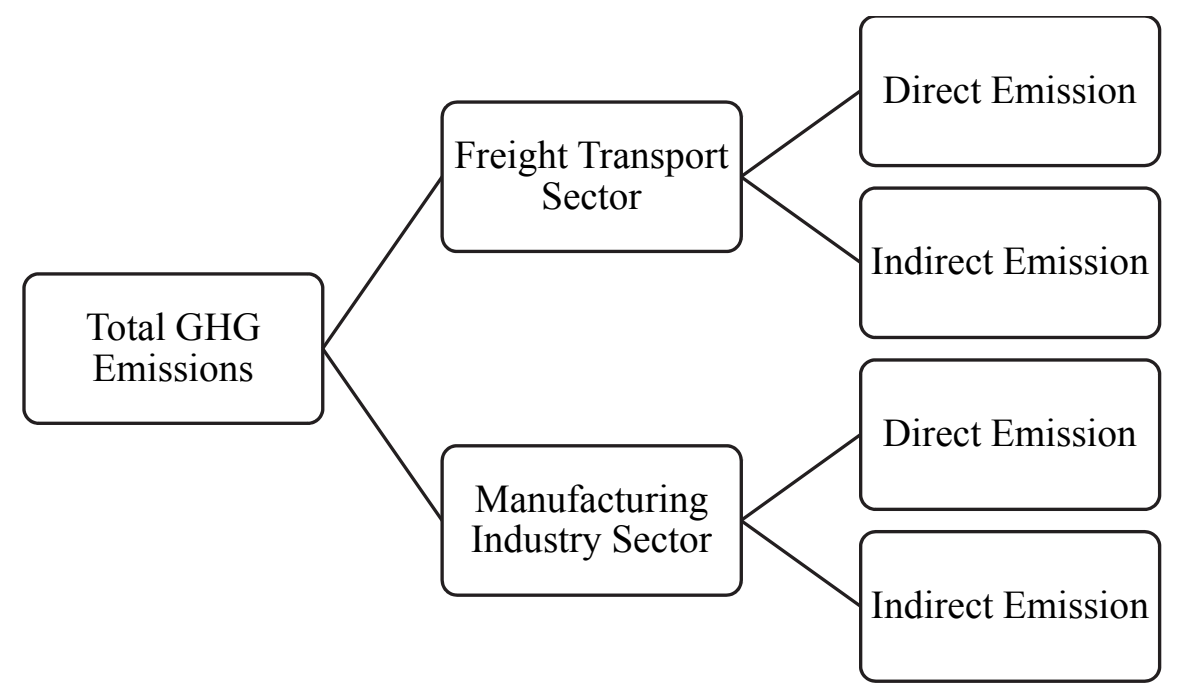

Fig. 1. The classification of emissions in this article

There are three common carbon policies, namely: carbon emission tax, inflexible cap, the cap-and-trade (Hua et al., 2011; Benjaafar et al., 2012; Hoen et al., 2014). Policymakers can also provide penalties and incentives to reduce emission or impose costs on carbon emissions. A firm can reduce its carbon emission by changing its production, inventory, warehousing, logistics and transportation (Hua et al., 2011; Benjaafar et al., 2012). For more details, the firm can use less polluting generators (boilers), machines or vehicles (direct emissions). While the firm can reduce their carbon emission by using cleaner or environmentally friendly energy sources for indirect emission (Helmrich et al., 2015). This paper developed a mathematical model of a supply chain, i.e. GHG emissions from transport and industrial sectors. The objective was to minimize the integrated costs of supply chain and total emissions produced by these sectors. Subsequently, we analyzed of how imposing on carbon emission tax, penalty and incentive policies impacts the optimal decision variables.

The rest of this paper is organized as follows. The existing literature is reviewed in Section 2. Section 3 describes the problem description, notation, and assumptions. Section 4 develops two mathematical models (with and without penalty and incentive policies) and solution algorithms. Sections 5 and 6 contain numerical example; analysis and discussion, and section 7 concludes the paper.

\section{Literature review}

In recent years, research dealing with supply chain inventory management system has attracted attention many scholars. One of the first works that studied the Joint Economic Lot Size model (JELS) was conducted by Goyal (1977). Banerjee (1986) relaxes the assumption of lot-for-lot policy and infinite 
production rate. Goyal (1988) developed a model with $\mathrm{Lu}$ (1995) relaxed the assumption of Goyal (1988) and specified the optimal production and shipment policies when the shipment sizes are equal. Goyal (1995) then developed a model where successive shipment sizes increase by a ratio equal to the production rate divided by the demand rate. Later, Hill (1997) considered the geometric growth factor as a decision variable and he suggested a solution method based on an exhaustive search for both the growth factor and the number of shipments. Based on previous researches, Hill (1999) developed a general optimal policy model. Most of these coordinated models assume as deterministic demand. In fact, the buyer has usually faced lead time and demand uncertainties. Liao and Shyu (1991) developed an inventory model with probability in which lead time is the unique variable. Later, Ben-Daya and Raouf (1994) extended Liao and Shyu's model (1991) model with lead time and ordering quantity as decision variables. Ouyang et al. (1996) generalized Ben-Daya and Raouf's model (1994) model by considering shortages. Moon and Choi (1998) and Hariga and Ben-Daya (1999) further improved and revised Ouyang et al.'s model (1996) by optimizing the reorder point. The integrated inventory models under stochastic environment were developed by Ben-Daya and Hariga (2004), Ouyang et al. (2004) and Jauhari et al. (2011).

Pioneering research works on carbon emission models can be found in Hua et al. (2011) and Wahab et al. (2011). Hua et al. (2011) adopted the emission constraints into classical EOQ model, i.e. carbon emission through a cap-and-trade system under the assumption that carbon emission is linear with the order quantity. Wahab et al. (2011) developed mathematical models: a domestic and an international supply chains that took the environmental impacts. Benjaafar et al. (2012) and Chen et al. (2013) developed emission constraints to a single-level lot sizing (EOQ) and an integrated lot sizing models with the dynamic demand under different carbon emission policies (carbon emission tax, inflexible cap, the cap-and-trade) and analyzed the trade-off between costs and emissions. Jaber et al. (2013) developed a mathematical model for a two-level supply chain with incorporating carbon emission tax and penalties to reduce emission amount. This model takes into the emission amount as a function of the production rate. Setup cost, holding cost and emission cost are involved in determining the optimal production rate. Hoen et al. (2014) studied the problem of transportation model selection with carbon emission regulations and stochastic demand. Helmrich et al. (2015) introduced integrated carbon emission constraints in lot sizing problems. The main difference among of the models of Helmrich et al. (2015) with Benjaafar et al. (2012) and Chen et al. (2013) is the type of emission constraints, that their functions of emissions are sensitive with setups and holding cost. Xu, et al. (2015) derived the optimal total emission and production quantities of products overall levels of the cap and analyzed the impact on these optimal decisions. Zanoni et al. (2014) extended the model of Jaber et al. (2013) with Vendor Managed Inventory and Consignment Stock system (VMI-CS). Bazan et al. (2015a) extended and compared the works of Jaber et al. (2013) and Zanoni et al. (2014) by developing the mathematical model for a two-echelon supply chain system that considered the energy used for production. Bazan et al. $(2015 b ; 2017)$ extended their previous work and investigated a reverse logistic model and considered emissions from manufacturing, remanufacturing and transportation activities.

The above-mentioned papers mostly focus on the single-echelon system or two-echelon system without incorporating transportation costs. The inventory-theoretic model with transportation and inventory costs was first introduced by Baumol and Vinod (1970). Lippman (1971) assumed transportation cost with a constant cost per truckload. Langley (1980) considered actual freight rates function into lot sizing decision. Carter and Ferrin (1996) developed a lot-sizing model using enumerations techniques that consider actual freight rate schedules to determining the optimal order quantity. Swenseth and Godfrey (2002) proposed a method to approximate the actual transportation cost with actual truckload freight rates. Abad and Aggarwal (2005) involved transportation cost into inventory model and determining lotsize and pricing decision with downward sloping demand. Nie et al. (2006) and Ertogral et al. (2007) presented an integrated inventory model with transportation cost. Ben-Daya et al. (2008) presented joint economic lot sizing models with different shipment policies. Mendoza and Ventura (2008) presented an algorithm based on a grossly simplified freight rate structure for truckload (TL) or least-then-truckload 
(LTL) shipments. Rieksts and Ventura $(2008$; 2010) considered a combination of two different modes of transportation: LTL and FTL (full truckload). In the field of supply chain coordination, researches such as Viau et al. (2009) and Kim and Goyal (2009) focused on the integration of inventory and transportation decisions. Yildirmaz et al. (2009) considered joint pricing and lot-sizing decision with transportation. Leaveano et al. (2014a, 2014b) extended Nie et al's model (2006) with distance parameter. Gurtu et al. (2015) developed the inventory models with involving the fuel price.

Addressing the gap between the studies, this paper developed JELS model by incorporating FTL and TL carriers, GHG emission and stochastic demand for a two-level supply chain between a manufacturer and a buyer. We assume that GHG emissions are produced by direct and indirect emissions of industrial and transport sectors. The Government can provide penalties and incentives to reduce emissions. Therefore, we developed a JELS model involving the penalty, incentive and industrial and transport emissions.

\section{Problem description, notation, and assumptions}

\subsection{Problem description}

This paper studied a supply chain system and GHG emission. The GHG emission is one Key Environmental Performance Indicator (KePI) used as a tool to measure a company's sustainability performance of environmental aspect. The GHG Protocol defines direct and indirect emissions as follows (www.ghgprotocol.org):

1. Direct GHG emissions are the emissions from the sources owned or controlled by the reporting entity.

2. Indirect GHG emissions are the emissions as the consequences of the activities of the reporting entity but occur at the sources owned or controlled by another entity.

The GHG Protocol has been defining of how the companies should manage and establish three categories of emissions as shown in Table 1 (www.ghgprotocol.org).

\section{Table 1}

Three categories of emissions

\begin{tabular}{lll}
\hline Scope 1 (direct) & Scope 2 (indirect) & Scope 3 (other indirect) \\
\hline From sources owned or controlled by & Consumption of & From sources not owned or directly controlled by Other \\
a company: & purchased: & indirect emissions, such as: \\
- own vehicles and equipment & - electricity & - business travel \\
- fuel of production combustion & - heating & - employee travel \\
- wastewater treatment, etc & - hot water & - transport and distribution (related activities in vehicles \\
& - steam & not owned or controlled) \\
& - cooling & - electricity-related activities not covered in Scope 2 \\
& For internal use & - outsourced activities \\
& & - waste disposal, etc. \\
\hline
\end{tabular}

This paper considered a two-echelon supply chain system consisting of a manufacturer and a buyer. The buyer sells items to the end customers whose demand follows a normal distribution with a mean of $D$ and standard deviation of $\sigma$. The buyer orders the item at a constant lot of size $Q$ from the manufacturer. Once an order is placed, a fixed ordering cost $S_{b}$ incurs. The manufacturer produces the product in a batch size of $Q n$ with a finite production rate $P(P>D)$ with a fixed setup cost $S_{m}$. The manufacturer also produces the indirect $\left(E I_{1}\right)$ and direct $\left(E I_{2}\right)$ emission quantities to the atmosphere from its production facilities. Indirect emission is consumed by electricity $\left(e_{c o}\right)$, steam $\left(s_{c o}\right)$, heating $\left(h_{c o}\right)$, cooling $\left(c_{c o}\right)$ and loss of energy to produce a production quantity. While boiler (generator) directly produces direct emission to the atmosphere and also produces a production quantity. The manufacturer will pay the cost of emissions corresponding to the number of emissions produced and the Government's carbon emission taxes $\left(C_{G H G}\right)$. During the production period, when the first $Q$ units have been produced, the manufacturer 
may schedule to the third party (freight forwarding services) to pick-up its product. In this policy, the freight will give surcharge per shipment $(\theta)$ to the manufacturer and the manufacturer will send the invoice as freight costs to the buyer. The surcharge may consist of the setup cost for the fleet and material handling costs (www.fedex.com). In this policy, the manufacturer will not pay the transportation cost. As a consequence of the pick-up policy, the distance from the location from the freight to the buyer is $\left(2 d_{m}+d_{b}\right)$. We assume the distance between these parties is linear. The freight cost also influences the fuel prices $(\delta)$ and fuel consumed by diesel truck $(\gamma)$. The freight rate, $F_{x}$ is charged to the buyer. The buyer pays the freight rate to the freight for each shipment weight $\left(W_{x}\right)$ which is scheduled by the freight. In this activity, the freight will produce the transport indirect emission quantity $\left(E T_{1}\right)$. The buyer will receive the lot size of $Q$ with average every $D / Q$ unit of time the inventory level until to zero. The buyer will produce the transport direct emission quantity $\left(E T_{2}\right)$ in which the emission comes from the material handling process, such as fuel of forklift, etc. Similarly, the buyer also pays these quantity emissions with the carbon emission tax $\left(C_{G H G}\right)$. The Government made a penalty $(\rho)$ and incentive $(\eta)$ policies to reduce direct and indirect emissions from manufacturing industry and freight transport. The penalties are given if total emissions have exceeded the Emission Limit Value (ELV), otherwise, if total emissions are below the $E L V$ then the incentive will be provided so that it can be derived using improvement activities. The partial backorder $\left(\pi_{x}\right)$ and lost sales $\left(\pi_{0}\right)$ are permitted. The system description is illustrated in Figure 2 .

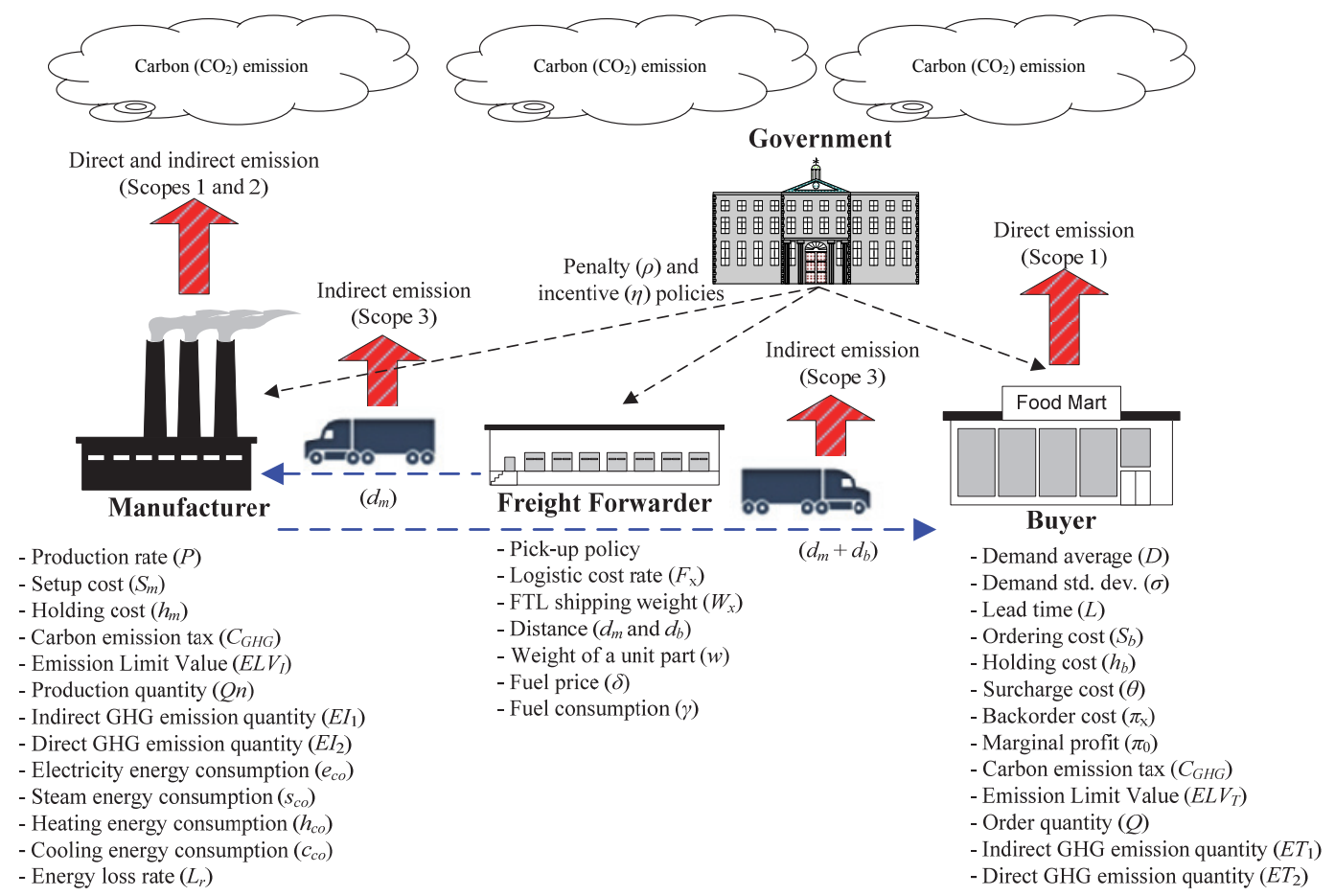

Fig. 2. The overview of problem in this paper

The following parameters and decision variables notation are listed below:

\subsection{General parameters}

$D \quad$ average demand of the buyer

$P \quad$ production rate of the manufacturer, $P>D$

(units/year)

$\sigma \quad$ standard deviation demand of the buyer

(units/year)

$L \quad$ length of the lead time for the buyer

(unit/week)

$S_{b} \quad$ buyer's ordering cost per order

$S_{m} \quad$ manufacturer's setup cost per setup

$h_{b} \quad$ holding cost of the buyer, $h_{b}>h_{m}$

$h_{m} \quad$ holding cost of the manufacturer 


\begin{tabular}{|c|c|c|}
\hline $\mathrm{C}_{G H G}$ & carbon emission tax & $\left(\$ /\right.$ ton $\left.\mathrm{CO}_{2}\right)$ \\
\hline$\rho$ & penalty, $\rho \geq \eta$ & $\left(\$ /\right.$ year/ton $\left.\mathrm{CO}_{2}\right)$ \\
\hline$\eta$ & incentive & $\left(\$ /\right.$ year/ton $\left.\mathrm{CO}_{2}\right)$ \\
\hline$E L V_{T}$ & transport emission limit value & (ton $\mathrm{CO}_{2}$ ) \\
\hline$E L V_{I}$ & industrial emission limit value & $\left(\right.$ ton $\left.\mathrm{CO}_{2}\right)$ \\
\hline$E_{T 1}$ & transport indirect emission quantity & $\left(\right.$ ton $\left.\mathrm{CO}_{2}\right)$ \\
\hline$E_{T 2}$ & transport direct emission quantity & $\left(\right.$ ton $\left.\mathrm{CO}_{2}\right)$ \\
\hline$E_{I 1}$ & industrial indirect emission quantity & (ton $\left.\mathrm{CO}_{2}\right)$ \\
\hline$E_{I 2}$ & industrial direct emission quantity & (ton $\left.\mathrm{CO}_{2}\right)$ \\
\hline$\theta$ & surcharge per shipment for pick-up policy & $(\$)$ \\
\hline$w$ & weight of a unit part & (lbs/unit) \\
\hline$\alpha$ & discount factor for LTL shipments, $0 \leq \alpha \leq 1$ & $(-)$ \\
\hline$F_{x}$ & the freight rate for full truckload (FTL) & $(\$ / \mathrm{lb} / \mathrm{mile})$ \\
\hline$F_{y}$ & the freight rate for partial load & $(\$ / \mathrm{lb} / \mathrm{mile})$ \\
\hline$W_{x}$ & full truckload (FTL) shipping weight & (lbs) \\
\hline$W_{y}$ & actual shipping weight & (lbs) \\
\hline$\pi_{\mathrm{x}}$ & backorder cost per unit of the buyer & $(\$)$ \\
\hline$\pi_{0}$ & marginal profit per unit of the buyer & $(\$)$ \\
\hline$\beta$ & the backorder ratio, $0 \leq \beta \leq 1$ & $(-)$ \\
\hline$B(r)$ & expected demand shortage at the end of the cycle & (units) \\
\hline$X$ & $\begin{array}{l}\text { the lead time demand, which follows a normal distribution } \\
\text { standard deviation } \sigma \sqrt{L}, X \sim N\left(D_{L}, \sigma \sqrt{L}\right)\end{array}$ & $\begin{array}{l}\text { with finite mean } D_{L} \text { and } \\
\text { (units) }\end{array}$ \\
\hline$J T C_{1}$ & joint total cost without penalty and incentive policies & (\$/year) \\
\hline$J T C_{2}$ & joint total cost with penalty and incentive policies & (\$/year) \\
\hline
\end{tabular}

\subsection{Parameters from transport sector}

$\delta \quad$ fuel price

$\gamma \quad$ fuel consumed by diesel truck

$d_{b} \quad$ distance from the freight to the buyer

$d_{m} \quad$ distance from the manufacturer to the freight

$\Delta_{T 1} \quad$ transport indirect emission factor

$\Delta_{T 2} \quad$ transport direct emission factor

(\$/liter)

(liters/mile)

(miles)

(miles)

(ton $\mathrm{CO}_{2} /$ liter)

(ton $\mathrm{CO}_{2} / \mathrm{lb}$ )

\subsection{Parameters from industry sector}

$e_{c o} \quad$ electricity energy consumption

(Kwh)

Sco steam energy consumption

(Kwh)

$h_{c o} \quad$ heating energy consumption

(Kwh)

$c_{c o} \quad$ cooling energy consumption

$L_{r} \quad$ energy loss rate

$\Delta_{I 1} \quad$ industrial indirect emission factor

(ton $\mathrm{CO}_{2} / \mathrm{Kwh}$ )

$\Delta_{I 2} \quad$ industrial direct emission factor

(ton $\mathrm{CO}_{2}$ /unit)

\subsection{Decision variables}

$Q \quad$ order quantity of the buyer

(units)

$k \quad$ safety factor of the buyer

$n$ the number of deliveries per one production cycle (integer)

(times)

$T E$ total emission quantity 
In addition, the following assumptions are made in deriving the model:

1. The model assumes a single item with a single-vendor and a single-buyer inventory system and involves a single freight provider.

2. We consider the pick-up policy which is offered by the freight provider. The product will be picked by the freight and delivered from the manufacturer's location to the buyer's location. In this policy, the buyer will be charged an additional charge (surcharge) with $\theta$ (in dollar) by the freight.

3. The product is manufactured with a finite production rate of $P$, where $P>D$.

4. The buyer orders a lot of size $Q$ and the manufacturer's produce $n Q$ with a finite production rate $P$ in one setup, but ship quantity $Q$ to the buyer over $n$ times. The vendor incurs a setup cost $S_{m}$ for each production run and the buyer incurs an ordering cost $S_{b}$ for each order of quantity $Q$.

5. The demand $X$ during lead time $L$ follows a normal distribution with mean $D_{L}$ and standard deviation $\sigma \sqrt{L}$.

6. Shortages are allowed with partial backorders and lost sales.

7. All items are purchased Free On Board (F.O.B) origin. The buyer incurs all the freight costs.

\section{Model}

In this section, we formulate an integrated inventory model with GHG emissions penalty and incentive policies, emission from transport and industry sectors, and stochastic demand.

\subsection{Buyer's total cost per year}

The total cost of the buyer is composed of ordering cost, holding cost, shortage cost, freight cost, surcharge cost and carbon emission cost. These components are evaluated as following:

\section{Ordering cost.}

The ordering cost per year $=\frac{D}{Q} S_{b}$

2. Holding cost. The expected net inventory level just before receipt of an order is $\left(R-D_{L}\right)$, and the expected net inventory level immediately after the successive order is $\left(Q+R-D_{L}\right)$. Hence, the average inventory over the cycle can be approximated by $\left(Q / 2+R-D_{L}\right)$. Therefore, the buyer's expected holding cost per unit time is $h_{b}\left(Q / 2+R-D_{L}\right)$. Using the same approach as in Montgomery et al. (1973), the expected net inventory level just before receipt of a delivery is $R-D_{L}+(1-\beta) B(r)$. The expected shortage quantity at the end of the cycle is given by $B(r)=$ $\sigma \sqrt{L} \psi(k)$, where, $\psi(k)=\phi(k)-k[1-\Phi(k)]$, and $\varnothing, \Phi$ denote the standard normal density function (p.d.f) and c.d.f., respectively. Where, $k \sigma \sqrt{L}=\left(R-D_{L}\right)$.

$$
\text { The holding cost per year }=h_{b}\left[\frac{Q}{2}+k \sigma \sqrt{L}+(1-\beta) \sigma \sqrt{L} \psi(k)\right]
$$

3. Shortage cost. As mentioned earlier, the lead time demand $X$ has a c.d.f. with finite mean $D_{L}$ and standard deviation $\sigma \sqrt{L}$. Shortage occurs when $X>r$, then, the expected shortage quantity at the end of the cycle is given by $B(r)$. Thus, the expected of backorders and lost sales per order is $\beta B(r)$ and $(1-\beta) B(r)$, respectively.

The shortage cost per year $=\frac{D}{Q}\left[\pi_{x} \beta+\pi_{0}(1-\beta)\right] \sigma \sqrt{L} \psi(k)$ 
4. Freight cost. We extended the work of Swenseth and Buffa (1990) and Gurtu et al. (2015) to determine the freight cost. Using the notations: $d_{m}$ is the distance from the manufacturer to the freight (in miles), $d_{b}$ is the distance from the freight to the buyer (in miles), $\delta$ is the fuel price (\$/liter) and $\gamma$ is the fuel consumption (liters/mile). Let $F_{x}$ set the lower bound when shipping weights $\left(W_{y} \leq W_{x}\right)$. Hence, the freight rate $\left(F_{y}\right)$ for the actual shipping weight $\left(W_{y}\right)$ is as follows:

$$
F_{y}=\frac{F_{x} W_{x}+\delta \gamma}{W_{y}}
$$

The freight cost rate per pound per mile can be represented by:

$F=\alpha F_{y}+(1-\alpha)\left[F_{x}+\frac{\delta \gamma}{W_{y}}\right]$

Subject to $0 \leq \alpha \leq 1$

Upon substitution of Eq. (4) into Eq. (5) and simplifying, the resulting unit rate is

$$
F=F_{x}+\frac{\delta \gamma}{W_{y}}+\alpha\left[\frac{F_{x}\left(W_{x}-W_{y}\right)}{W_{y}}\right]
$$

By substituting the Eq. (6) into the total freight, we have: (Swenseth \& Buffa, 1990; Swenseth \& Godfrey, 2002)

$$
F_{z}=\left\{F_{x}+\frac{\delta \gamma}{W_{y}}+\alpha\left[\frac{F_{x}\left(W_{x}-W_{y}\right)}{W_{y}}\right]\right\} D\left(2 d_{m}+d_{b}\right) w
$$

where the actual shipping weight $\left(W_{y}=Q w\right)$ and 2 represents a pick-up policy from the freight to the manufacturer and from the manufacturer to the buyer.

The freight cost per year $=\frac{D}{Q}\left[\alpha F_{x} W_{x}+\delta \gamma\right]\left(2 d_{m}+d_{b}\right)+D(1-\alpha) F_{x} w\left(2 d_{m}+d_{b}\right)$

5. Surcharge cost. In this policy, we assume that the freight offers pick-up services (by on call) and the products will be picked from the manufacturer and delivered to the buyer with the surcharge per shipment, $\theta$ (in dollar). This fee includes ordering cost by phone call, material handling cost, labor cost, wooden pallet collars etc.

The surcharge cost per year $=\frac{D}{Q} \theta$

6. Carbon emission cost. As described in the problem description, transport GHG emissions are divided into two parts: indirect and direct transport emissions, with the notations: $\Delta_{T 1}$ is transport indirect emission factor (ton $\mathrm{CO}_{2}$ per liter), $\gamma$ is the fuel consumption (liters per mile), $d_{m}$ is the distance from the manufacturer to the freight (in miles), and $d_{b}$ is the distance from the freight to the buyer (in miles).

Transport indirect emission quantity $E T_{1}=\Delta_{T 1} \gamma\left(2 d_{m}+d_{b}\right)$

For the transport direct emission quantity, we use the notations: $\Delta_{T 2}$ is transport direct emission factor (ton $\mathrm{CO}_{2}$ per $\mathrm{lb}$ ), $w$ is the weight of unit part (lbs per unit) and $Q$ is order quantity (units).

Transport direct emission quantity $E T_{2}=\Delta_{T 2} w Q$

The carbon emission tax $\left(C_{G H G}\right)$, hence total transport emission cost per year with indirect and direct emissions is given by: 
Total transport emission cost per year $=\frac{D}{Q}\left(E T_{1}+E T_{2}\right) C_{G H G}$

The Eq. (12) can be rewritten into:

Total transport emission cost per year $=D\left[\frac{\Delta_{T 1} \gamma\left(2 d_{m}+d_{b}\right)}{Q}+\Delta_{T 2} w\right] C_{G H G}$

Finally, the total cost for the buyer per year without penalty and incentive policies can be formulated by considering Eqs. (1)-(3), Eq. (8), Eq. (9) and Eq. (13). The total cost for the buyer $\left(T C_{b 1}\right)$. One has:

$$
\begin{aligned}
T C_{b 1}(Q, k)= & \frac{D}{Q} S_{b}+h_{b}\left[\frac{Q}{2}+k \sigma \sqrt{L}+(1-\beta) \sigma \sqrt{L} \psi(k)\right]+\frac{D}{Q} \theta \\
& +\frac{D}{Q}\left[\pi_{x} \beta+\pi_{0}(1-\beta)\right] \sigma \sqrt{L} \psi(k)+\frac{D}{Q}\left[\alpha F_{x} W_{x}+\delta \gamma\right]\left(2 d_{m}+d_{b}\right) \\
& +D(1-\alpha) F_{x} w\left(2 d_{m}+d_{b}\right)+D\left[\frac{\Delta_{T 1} \gamma\left(2 d_{m}+d_{b}\right)}{Q}+\Delta_{T 2} w\right] C_{G H G}
\end{aligned}
$$

\subsection{Manufacturer's total cost per year}

Total cost for the manufacturer consists of setup cost, holding cost and carbon emission cost. These components are evaluated as following:

1. Setup cost. The manufacturer produces $n Q$ in one production run time. Therefore, the setup cost

$$
\text { per year }=\frac{D}{n Q} S_{m}
$$

2. Holding cost. The manufacturer's inventory per cycle can be calculated by subtracting the buyer's accumulated inventory level from the manufacturer's accumulated inventory level. Hence, the manufacturer' average inventory level per year is given by $=\frac{Q}{2}\left[n\left(1-\frac{D}{P}\right)-1+\frac{2 D}{P}\right]$.

The manufacturer's holding cost per year is $=h_{m} \frac{Q}{2}\left[n\left(1-\frac{D}{P}\right)-1+\frac{2 D}{P}\right]$

3. Carbon emission cost. As the same describe in the buyer's carbon emission, industrial GHG emissions are divided into two parts: indirect and direct emissions. We used the notations: $\Delta_{I 1}$ is industrial indirect emission factor (ton $\mathrm{CO}_{2}$ per $\mathrm{Kwh}$ ), $e_{c o}$ is the electricity energy consumption $(\mathrm{Kwh}), s_{c o}$ is the steam energy consumption (Kwh), $h_{c o}$ is the heating energy consumption (Kwh) and $c_{c o}$ is the cooling energy consumption (Kwh) and $L_{r}$ is energy loss rate (\%).

$$
\text { Industrial indirect emission quantity } E I_{1}=\Delta_{I 1}\left(e_{c o}+s_{c o}+h_{c o}+c_{c o}\right) L_{r}
$$

We use the notations: $\Delta_{I 2}$ is industrial direct emission factor (ton $\mathrm{CO}_{2}$ per unit), $n Q$ is production quantity (units) to determine the industrial direct emission quantity.

$$
\text { Industrial direct emission quantity } E I_{2}=\Delta_{I 2} n Q
$$

Hence, total industrial emission cost per year with indirect and direct emissions is given by:

Total industrial emission cost per year $=\frac{D}{n Q}\left(E I_{1}+E I_{2}\right) C_{G H G}$

The Eq. (19) can be rewritten into:

Total industrial emission cost per year $=D\left[\frac{\Delta_{I 1}\left(e_{c o}+s_{c o}+h_{c o}+c_{c o}\right) L_{r}}{n Q}+\Delta_{I 2}\right] C_{G H G}$ 
Finally, the total cost for the manufacturer per year without penalty and incentive policies can be formulated by considering Eqs. (15-16) and Eq. (20). The total cost for the manufacturer $\left(T C_{m 1}\right)$. One has:

$$
T C_{m 1}(Q, n)=\frac{D}{n Q} S_{m}+h_{m} \frac{Q}{2}\left[n\left(1-\frac{D}{P}\right)-1+\frac{2 D}{P}\right]+D\left[\frac{\Delta_{I 1}\left(e_{c o}+s_{c o}+h_{c o}+c_{c o}\right) L_{r}}{n Q}+\Delta_{I 2}\right] C_{G H G}
$$

Accordingly, the integrated total cost for a single manufacturer and a single buyer inventory system without penalty and incentive policies is the sum of the Eq. (14) and Eq. (21). One has:

$$
\begin{aligned}
& \min J T C_{1}(Q, k, n)=T C_{b 1}(Q, k)+T C_{m 1}(Q, n) \\
& =\frac{D}{Q}\left\{S_{b}+\theta+\left[\alpha F_{x} W_{x}+\gamma\left(\delta+\Delta_{T 1} C_{G H G}\right)\right]\left(2 d_{m}+d_{b}\right)+\left[\pi_{x} \beta+\pi_{0}(1-\beta)\right] \sigma \sqrt{L} \psi(k)\right. \\
& \left.+\frac{S_{m}+\Delta_{I 1}\left(e_{c o}+s_{c o}+h_{c o}+c_{c o}\right) L_{r} C_{G H G}}{n}\right\} \\
& +h_{b}[k \sigma \sqrt{L}+(1-\beta) \sigma \sqrt{L} \psi(k)]+\frac{Q}{2}\left\{h_{b}+h_{m}\left[n\left(1-\frac{D}{P}\right)-1+\frac{2 D}{P}\right]\right\} \\
& +D\left[(1-\alpha) F_{x} w\left(2 d_{m}+d_{b}\right)+\left(\Delta_{T 2} w+\Delta_{I 2}\right) C_{G H G}\right]
\end{aligned}
$$

\subsection{Penalty and incentive policies}

To formulate the penalty and incentive policies, the Government sets the overall limit on emission (also called "cap") as a basis value at first. Figure 3 illustrates the penalty and incentive policies.

\section{The transport emission model with the penalty and incentive policies}

Fig. 3 describes that if total transport emission exceeds the $E L V_{T},\left(\sum_{i=1}^{2} E_{T i}>E L V_{T}\right)$, the buyer would have to pay an exceed emissions (penalty and loss of incentive) from the gap of $\sum_{i=1}^{2} E_{T i}$ and $E L V_{T}$. Otherwise, if total emission is lower than the $E L V_{T},\left(\sum_{i=1}^{2} E_{T i}<E L V_{T}\right)$ then the buyer will receive the Government's incentive and benefit of the penalty. Furthermore, the transport emission model with the penalty and incentive policies is given by:

$$
\tau_{T}=\rho\left(\sum_{i=1}^{2} E_{T i}-E L V_{T}\right)-\eta\left(E L V_{T}-\sum_{i=1}^{2} E_{T i}\right)
$$

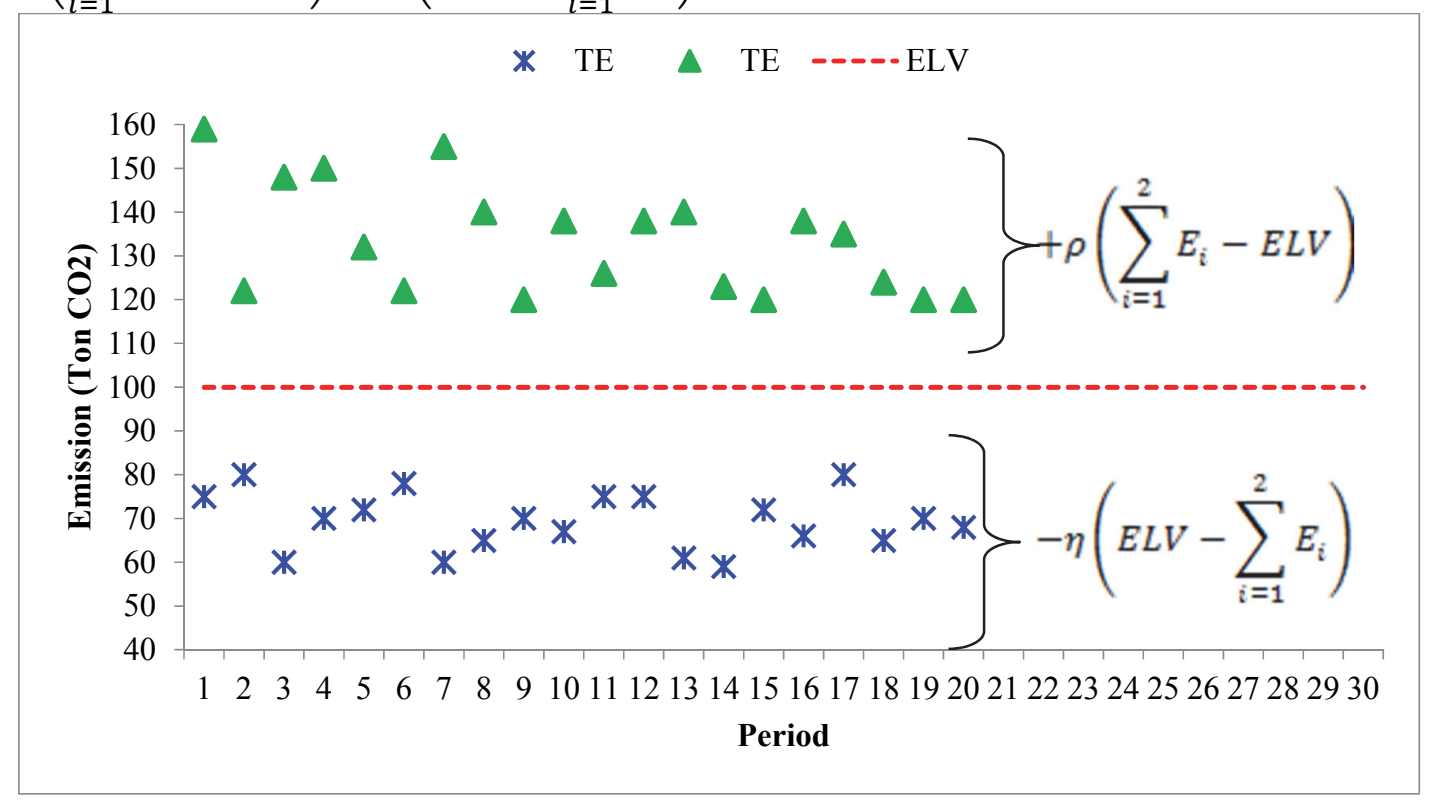

Fig. 3. The illustrated of penalty and incentive formulas 
The industrial emission model with the penalty and incentive policies

The penalty and incentive from industry sector will be paid by the manufacturer. Similarly, the model of the industrial emission with the penalty and incentive policies is given by:

$$
\tau_{I}=\rho\left(\sum_{i=1}^{2} E_{I i}-E L V_{I}\right)-\eta\left(E L V_{I}-\sum_{i=1}^{2} E_{I i}\right)
$$

Total transport and industrial emissions with the penalty and incentive policies

Accordingly, the formula of transport and industrial emissions with the penalty and incentive policies is the sum of the Eqs. (23-24). One has:

$$
\begin{aligned}
& \tau_{T}+\tau_{I}=\rho\left(\sum_{i=1}^{2} E_{T i}-E L V_{T}\right)-\eta\left(E L V_{T}-\sum_{i=1}^{2} E_{T i}\right)+\rho\left(\sum_{i=1}^{2} E_{I i}-E L V_{I}\right)-\eta\left(E L V_{I}-\sum_{i=1}^{2} E_{I i}\right) \\
& \tau_{T}+\tau_{I}=\rho \sum_{i=1}^{2} E_{T i}-\rho E L V_{T}-\eta E L V_{T}+\eta \sum_{i=1}^{2} E_{T i}+\rho \sum_{i=1}^{2} E_{I i}-\rho E L V_{I}-\eta E L V_{I}+\eta \sum_{i=1}^{2} E_{I i} \\
& \tau_{T}+\tau_{I}=-\rho E L V_{T}-\eta E L V_{T}-\rho E L V_{I}-\eta E L V_{I}+\rho \sum_{i=1}^{2} E_{T i}+\eta \sum_{i=1}^{2} E_{T i}+\rho \sum_{i=1}^{2} E_{I i}+\eta \sum_{i=1}^{2} E_{I i} \\
& \tau_{T}+\tau_{I}=(\rho+\eta)\left(-E L V_{T}-E L V_{I}\right)+(\rho+\eta)\left(\sum_{i=1}^{2} E_{T i}+\sum_{i=1}^{2} E_{I i}\right) \\
& \tau_{T}+\tau_{I}=(\rho+\eta)\left(\sum_{i=1}^{2} E_{T i}+\sum_{i=1}^{2} E_{I i}-E L V_{T}-E L V_{I}\right)
\end{aligned}
$$

By substituting the Eqs. (10-11, 17-18) to Eq. (25), the Eq. (25) can be rewritten into:

$$
\tau_{T}+\tau_{I}=(\rho+\eta)\left[\Delta_{T 1} \gamma\left(2 d_{m}+d_{b}\right)+\Delta_{I 1}\left(e_{c o}+s_{c o}+h_{c o}+c_{c o}\right) L_{r}+\left(\Delta_{T 2} w+\Delta_{I 2} n\right) Q-E L V_{T}-E L V_{I}\right]
$$

Finally, adding the Eq. (26) to the Eq. (22), we find the integrated total cost for a single manufacturer and a single buyer inventory system with the penalty and incentive. One has:

$$
\begin{aligned}
& \min J T C_{2}(Q, k, n)=J T C_{1}(Q, k, n)+\tau_{T}(Q)+\tau_{I}(Q, n) \\
& =\frac{D}{Q}\left\{S_{b}+\theta+\left[\alpha F_{x} W_{x}+\gamma\left(\delta+\Delta_{T 1} C_{G H G}\right)\right]\left(2 d_{m}+d_{b}\right)+\left[\pi_{x} \beta+\pi_{0}(1-\beta)\right] \sigma \sqrt{L} \psi(k)\right. \\
& \left.\quad+\frac{S_{m}+\Delta_{I 1}\left(e_{c o}+s_{c o}+h_{c o}+c_{c o}\right) L_{r} C_{G H G}}{n}\right\} \\
& +h_{b}[k \sigma \sqrt{L}+(1-\beta) \sigma \sqrt{L} \psi(k)]+\frac{Q}{2}\left\{h_{b}+h_{m}\left[n\left(1-\frac{D}{P}\right)-1+\frac{2 D}{P}\right]\right\} \\
& +D\left[(1-\alpha) F_{x} w\left(2 d_{m}+d_{b}\right)+\left(\Delta_{T 2} w+\Delta_{I 2}\right) C_{G H G}\right] \\
& +(\rho+\eta)\left[\Delta_{T 1} \gamma\left(2 d_{m}+d_{b}\right)+\Delta_{I 1}\left(e_{c o}+s_{c o}+h_{c o}+c_{c o}\right) L_{r}+\left(\Delta_{T 2} w+\Delta_{I 2} n\right) Q-E L V_{T}-E L V_{I}\right]
\end{aligned}
$$

\subsection{Solution procedure}

Our objective is to find the optimal decision variables which minimize the above functions. For fixed $n$, we take the partial derivatives of Eq. (22) with respect to $Q$ and $k$, respectively. The results for the first model, we obtain: 


$$
\begin{aligned}
& 464 \\
& \begin{aligned}
\frac{\partial J T C_{1}(Q, k, n)}{\partial Q}= & \frac{-D}{Q^{2}}\left\{S_{b}+\theta+\left[\alpha F_{x} W_{x}+\gamma\left(\delta+\Delta_{T 1} C_{G H G}\right)\right]\left(2 d_{m}+d_{b}\right)+\left[\pi_{x} \beta+\pi_{0}(1-\beta)\right] \sigma \sqrt{L} \psi(k)\right. \\
& \left.+\frac{S_{m}+\Delta_{I 1}\left(e_{c o}+s_{c o}+h_{c o}+c_{c o}\right) L_{r} C_{G H G}}{n}\right\}+\frac{1}{2}\left\{h_{b}+h_{m}\left[n\left(1-\frac{D}{P}\right)-1+\frac{2 D}{P}\right]\right\}
\end{aligned}
\end{aligned}
$$

and

$$
\frac{\partial J T C_{1}(Q, k, n)}{\partial k}=\frac{D}{Q}\left\{\pi_{x} \beta+\pi_{0}(1-\beta) \sigma \sqrt{L}[\Phi(k)-1]\right\}+h_{b}\{\sigma \sqrt{L}+(1-\beta) \sigma \sqrt{L}[\Phi(k)-1]\}
$$

By setting Eq. (27-28) equal to zero and solving for $Q$ and $\Phi(k)$. One has:

$$
Q_{1}^{*}=\sqrt{\frac{2 D\left\{\begin{array}{c}
S_{b}+\theta+\left[\alpha F_{x} W_{x}+\gamma\left(\delta+\Delta_{T 1} C_{G H G}\right)\right]\left(2 d_{m}+d_{b}\right) \\
+\left[\pi_{x} \beta+\pi_{0}(1-\beta)\right] \sigma \sqrt{L} \psi(k)+\frac{S_{m}+\Delta_{I 1}\left(e_{c o}+s_{c o}+h_{c o}+c_{c o}\right) L_{r} C_{G H G}}{n}
\end{array}\right.}{h_{b}+h_{m}\left[n\left(1-\frac{D}{P}\right)-1+\frac{2 D}{P}\right]}}
$$

and

$$
\Phi\left(k_{1}^{*}\right)=1-\frac{h_{b} Q_{1}}{\left[\pi_{x} \beta+\pi_{0}(1-\beta)\right] D+h_{b} Q_{1}(1-\beta)}
$$

In order to examine the effect of $n$ on $J T C_{1}(Q, k, n)$, we take the first and the second partial derivatives of Eq. (22) with respect to $n$. One has:

$$
\frac{\partial J T C_{1}(Q, k, \mathrm{n})}{\partial n}=-\frac{S D}{n^{2} Q}+\frac{Q}{2} h_{v}\left(1-\frac{D}{P}\right)
$$

and

$$
\frac{\partial^{2} J T C_{1}(Q, k, n)}{\partial n^{2}}=2 \frac{S \cdot D}{n^{3} \cdot Q}>0
$$

This show that $J T C_{1}(Q, k, n)$ is a convex function in $n$, for fixed $(Q, k)$. Thus, the search finding the optimal number of deliveries, $n^{*}$ is reduced to finding a local optimal solution. In the same way the first model, to obtain the minimum of Eq. (27), take the first partial derivatives of $J T C_{2}(Q, k, n)$ with respect to $Q$ and $k$ and setting them to zero. One has:

$$
Q_{2}^{*}=\sqrt{\frac{2 D\left\{\begin{array}{c}
S_{b}+\theta+\left[\alpha F_{x} W_{x}+\gamma\left(\delta+\Delta_{T 1} C_{G H G}\right)\right]\left(2 d_{m}+d_{b}\right) \\
+\left[\pi_{x} \beta+\pi_{0}(1-\beta)\right] \sigma \sqrt{L} \psi(k)+\frac{S_{m}+\Delta_{I 1}\left(e_{c o}+S_{c o}+h_{c o}+c_{c o}\right) L_{r} C_{G H G}}{n}
\end{array}\right.}{h_{b}+h_{m}\left[n\left(1-\frac{D}{P}\right)-1+\frac{2 D}{P}\right]+2(\rho+\eta)\left(\Delta_{T 2} w+\Delta_{I 2} n\right)}}
$$

and

$$
\Phi\left(k_{2}^{*}\right)=1-\frac{h_{b} Q_{2}}{\left[\pi_{x} \beta+\pi_{0}(1-\beta)\right] D+h_{b} Q_{2}(1-\beta)}
$$

\subsection{Solution algorithm}

The following algorithm is developed to find the optimal values for order quantity, safety factor, total emission, and the optimal number of deliveries in one production cycle.

Step 1 Set $n=1$.

Step 2 Set $k_{0}=0$ [implies $\psi\left(k_{0}\right)=0.39894$ and $\Phi\left(k_{0}\right)=0.50$ ] for each model. 
Step 3 Evaluate the optimal $Q^{*}$.

(Step 3.1) For the first model, find $Q_{1}^{*}$ by substituting $\psi\left(k_{0}\right)$ into Eq. (30)

(Step 3.2) For the second model, find $Q_{2}^{*}$ by substituting $\psi\left(k_{0}\right)$ into Eq. (34).

Step 4 Calculate actual shipping weight, $\left(W_{y}=Q^{*} w\right)$. If $\left(W_{y} \leq W_{x}\right)$ is satisfied go to Step 5. Otherwise, go to Step 6 if truckload constraint is not satisfied $\left(W_{y}>W_{x}\right)$.

(Step 4.1) For the first model, $\left(W_{y 1}^{*}=Q_{1}^{*} w\right)$.

(Step 4.2) For the second model, $\left(W_{y 2}^{*}=Q_{2}^{*} w\right)$.

Step 5 Revised the optimal lot size and go to Step 6.

(Step 5.1) For the first model, $\left(Q_{1}^{*}=\frac{W_{x}}{w}\right)$.

(Step 5.2) For the second model, $\left(Q_{2}^{*}=\frac{W_{x}}{w}\right)$.

Step 6 Determine of $\Phi\left(k_{i}^{*}\right)$ then find $k_{\text {i from }} \Phi\left(k_{i}\right)$ by checking the normal table.

(Step 6.1) For the first model using Eq. (31).

(Step 6.2) For the second model using Eq. (35).

Step 7 Repeat Step $2-6$ until no change occurs in the values of $Q$ and $k$. The result is denoted by $\left(Q^{*}\right.$, $k^{*}$ ) for both models.

Step 8 Compute the cost functions.

(Step 8.1) For the first model using Eq. (22).

(Step 8.2) For the second model using Eq. (27).

Step 9 Set $n=n+1$, repeat step 2 for both models.

Step 10 Check and evaluate the cost function.

(Step 10.1) If $J T C_{1}\left(Q_{1\left(n_{1}\right)}^{*}, k_{1\left(n_{1}\right)}^{*}, n_{1}\right) \leq J T C_{1}\left(Q_{1\left(n_{1}-1\right)}^{*}, k_{1\left(n_{1}-1\right)}^{*}, n_{1}-1\right)$, then go to Step 9, otherwise go to step 11 on the first model.

(Step 10.2) If $\operatorname{JTC}_{2}\left(Q_{2\left(n_{2}\right)}^{*}, k_{2\left(n_{2}\right)}^{*}, n_{2}\right) \leq J T C_{2}\left(Q_{2\left(n_{2}-1\right)}^{*}, k_{2\left(n_{2}-1\right)}^{*}, n_{2}-1\right)$, then go to Step 9, otherwise go to step 11 on the second model.

Step 11 The optimal decision variables.

(Step 11.1) For the first model, $\left(Q_{1}^{*}, k_{1}^{*}, n_{1}^{*}\right)=\left(Q_{1\left(n_{1}\right)}^{*}, k_{1\left(n_{1}\right)}^{*}, n_{1}\right)$, then $\left(Q_{1}^{*}, k_{1}^{*}, n_{1}^{*}\right)$ is a set of optimal, therefore the optimal of total emission is $T E_{1}^{*}=\Delta_{T 1} \gamma\left(2 d_{m}+d_{b}\right)+$ $\Delta_{I 1}\left(e_{c o}+s_{c o}+h_{c o}+c_{c o}\right) L_{r}+\left(\Delta_{T 2} w+\Delta_{I 2} n_{1}^{*}\right) Q_{1}^{*}$.

(Step 11.2) The second model, $\left(Q_{2}^{*}, k_{2}^{*}, n_{2}^{*}\right)=\left(Q_{2\left(n_{2}\right)}^{*}, k_{2\left(n_{2}\right)}^{*}, n_{2}\right)$, then $\left(Q_{2}^{*}, k_{2}^{*}, n_{2}^{*}\right)$ is a set of optimal, therefore the optimal of total emission is $T E_{2}^{*}=\Delta_{T 1} \gamma\left(2 d_{m}+d_{b}\right)+$ $\Delta_{I 1}\left(e_{c o}+s_{c o}+h_{c o}+c_{c o}\right) L_{r}+\left(\Delta_{T 2} w+\Delta_{I 2} n_{2}^{*}\right) Q_{2}^{*}$.

\section{Numerical example}

This section demonstrates of the models to obtain the optimal solution. Table 2 shows the set data for our example. Implementing two models by optimizing the cost function, we found the optimal solutions as given in Table 3. The minimum joint total cost for the first model (without penalty and incentive policies) is $\$ 95,998.58 /$ year with the optimal order quantity, $Q^{*}=677,67$ units; actual weight, $W_{y}{ }^{*}=$ $14,908.77 \mathrm{lbs}$; safety factor, $k^{*}=2.25$; number of delivery, $n^{*}=3$ times, total transport emission quantity, $E_{T}{ }^{*}=37.67$ ton $\mathrm{CO}_{2}$ and total industrial emission quantity, $E_{I}{ }^{*}=107.10$ ton $\mathrm{CO}_{2}$. The emissions results show that the total transport emission quantity is below the $E L V_{T}\left(50\right.$ ton $\left.\mathrm{CO}_{2}\right)$ and the total industrial emission quantity is higher than the $E L V_{I}\left(100\right.$ ton $\left.\mathrm{CO}_{2}\right)$. With the same parameters, the optimal solutions of the second model (involving the penalty and incentive policies) yields a minimum joint total cost of $\$ 92,586.91 /$ year with $Q^{*}=438,05$ units; $W_{y}{ }^{*}=9,637.17 \mathrm{lbs} ; k^{*}=2.42 ; n^{*}=4$ times, $E_{T}{ }^{*}=24.50$ ton $\mathrm{CO}_{2}$ and $E_{I}{ }^{*}=104.39$ ton $\mathrm{CO}_{2}$. Due to the transport emission quantity below the $E L V_{T}$ and the industrial emission quantity above the $E L V_{I}$, then the impact is the provision of incentives and penalties by the Government to the buyer and the manufacturer, respectively. So, the penalty and incentive policies have contributed in reducing emissions. The second model gives an impact to a decreased transport emission quantity with a saving of 13.18 ton $\mathrm{CO}_{2}(34.98 \%)$. It is affected from the actual weight on the second model that is smaller than the actual weight on the first model $(9,637.17<14,908.77)$, because the actual 
weight is direct emission $\left(W_{y}{ }^{*}=Q^{*} w\right)$. The saving of the industrial emission comes from production quantity (direct emission) on the second model $Q_{2}{ }^{*} n_{2}{ }^{*}=1,752.20$ units that are smaller than the first model of $Q_{1}{ }^{*} n_{1}{ }^{*}=2,033.01$ units with a saving of 2.71 ton $\mathrm{CO}_{2}(2.53 \%)$. The saving of total emission quantity is 15.89 ton $\mathrm{CO}_{2}(10.97 \%)$. The joint total cost saving on both models is $\$ 3,411.67$ (3.55\%).

Table 2

Parameters and values for numerical example

\begin{tabular}{|c|c|c|c|}
\hline & Parameters & Unit & Values \\
\hline \multirow[t]{21}{*}{ General } & 1. Average of demand $(D)$ & units/year & 10,000 \\
\hline & 2. Production rate $(P)$ & units/year & 40,000 \\
\hline & 3. Standard deviation of demand $(\sigma)$ & unit/week & 7 \\
\hline & 4. Lead time $(L)$ & days & 56 \\
\hline & 5. Buyer's ordering cost per order $\left(S_{b}\right)$ & $\$$ & 30 \\
\hline & 6. Manufacturing setup cost per setup $\left(S_{m}\right)$ & $\$$ & 3,600 \\
\hline & 7. Buyer's holding cost $\left(h_{b}\right)$ & \$/unit/year & 45 \\
\hline & 8. Manufacturer's holding cost $\left(h_{m}\right)$ & \$/unit/year & 38 \\
\hline & 9. Carbon emission tax $\left(C_{G H G}\right)$ & $\$ /$ ton $\mathrm{CO}_{2}$ & 20 \\
\hline & 10. Penalty $(\rho)$ & $\$ /$ year/ton $\mathrm{CO}_{2}$ & 300 \\
\hline & 11. Incentive $(\eta)$ & $\$ /$ year/ton $\mathrm{CO}_{2}$ & 125 \\
\hline & 12. Transport emission limit value $\left(E L V_{T}\right)$ & ton $\mathrm{CO}_{2}$ & 50 \\
\hline & 13. Industrial emission limit value $\left(E L V_{I}\right)$ & ton $\mathrm{CO}_{2}$ & 100 \\
\hline & 14. Buyer's surcharge of pick-up per shipment $(\theta)$ & $\$$ & 14 \\
\hline & 15. Weight of a unit part (w) & lbs/unit & 22 \\
\hline & 16. Discount factor for LTL shipment $(\alpha)$ & - & 0.11246 \\
\hline & 17. Freight rate $\left(F_{x}\right)$ & \$/lb/mile & 0.000040217 \\
\hline & 18. Full truckload shipping weight $\left(W_{x}\right)$ & lbs & 46,000 \\
\hline & 19. Backorder cost $\left(\pi_{\mathrm{x}}\right)$ & $\$$ & 100 \\
\hline & 20. Marginal profit $\left(\pi_{0}\right)$ & $\$$ & 300 \\
\hline & 21. Backorder ratio $(\beta)$ & - & 0.25 \\
\hline \multirow[t]{6}{*}{ Transport sector } & 1. Fuel price $(\delta)$ & \$/liter & 1.02 \\
\hline & 2. Fuel consumption $(\gamma)$ & liters/mile & 0.63569 \\
\hline & 3. Distance from the freight to the buyer $\left(d_{b}\right)$ & miles & 600 \\
\hline & 4. Distance from the manufacturer to the freight $\left(d_{m}\right)$ & miles & 50 \\
\hline & 5. Transport indirect emission factor $\left(\Delta_{T 1}\right)$ & ton $\mathrm{CO}_{2} /$ liter & 0.01268 \\
\hline & 6. Transport direct emission factor $\left(\Delta_{T 2}\right)$ & ton $\mathrm{CO}_{2} / \mathrm{lb}$ & 0.00250 \\
\hline \multirow[t]{7}{*}{ Industry sector } & 1. Electricity energy consumption $\left(e_{c o}\right)$ & Kwh & 154,556 \\
\hline & 2. Steam energy consumption $\left(s_{c o}\right)$ & Kwh & 115,917 \\
\hline & 3. Heating energy consumption $\left(h_{c o}\right)$ & Kwh & 38,639 \\
\hline & 4. Cooling energy consumption $\left(c_{c o}\right)$ & Kwh & 77,278 \\
\hline & 5. Energy loss rate $\left(L_{r}\right)$ & - & $1 \%$ \\
\hline & 6. Industrial indirect emission factor $\left(\Delta_{I 1}\right)$ & ton $\mathrm{CO}_{2} / \mathrm{Kwh}$ & 0.02264 \\
\hline & 7. Industrial direct emission factor $\left(\Delta_{I 2}\right)$ & ton $\mathrm{CO}_{2}$ /unit & 0.00965 \\
\hline
\end{tabular}

\section{Table 3}

The comparison of model 1 and model 2

\begin{tabular}{lll}
\hline & Model 1 & Model 2 \\
\hline Order quantity (units) & 677.67 & 438.05 \\
Actual weight (lbs) & $14,908.77$ & $9,637.17$ \\
Safety factor & 2.25 & 2.42 \\
Number of delivery & 3 & 4 \\
Total transport emission quantity $\left(\right.$ ton $\left.\mathrm{CO}_{2}\right)$ & 37.67 & 24.50 \\
Total industrial emission quantity (ton $\left.\mathrm{CO}_{2}\right)$ & 107.10 & 104.39 \\
Total emission $\left(\right.$ ton $\left.\mathrm{CO}_{2}\right)$ & 144.77 & 128.88 \\
Total cost of buyer $(\$ /$ year) & $45,222.49$ & $37,454.28$ \\
Total cost of manufacturer $(\$ /$ year) & $50,776.08$ & $55,132.63$ \\
Total cost $(\$ /$ year) & $95,998.58$ & $92,586.91$ \\
\hline a) Saving of total emission $\left[\right.$ ton $\left.\mathrm{CO}_{2},(\%)\right]$ & & $15.89 ;(10.97 \%)$ \\
b) Saving of total cost $[\$ /$ year, $(\%)]$ & & $3,411.67 ;(3.55 \%)$ \\
\hline
\end{tabular}

\footnotetext{
a) $\left(T E_{1}-T E_{2}\right) / T E_{1} \times 100 \%$

b) $\left(J T C_{1}-J T C_{2}\right) / J T C_{1} \times 100 \%$
} 
We compared and analyzed the results of independent and integrated policies. Table 4 shows that the total emission for an integrated policy is higher than the independent policy on the first model. A high value on total emission on an integrated policy is contributed from increasing of transport and industry decision variables simultaneously. It can be understood that the optimal actual weight transported on integrated policy $(14,908.77$ units) is higher than independent policy $(12.903 .51 \mathrm{lbs})$ in which both are derived from the optimal order quantity. It is the same in production quantity of integrated policy that is higher than independent policy. The integrated policy generates higher order quantity, aiming to reduce joint total cost. The total cost of independent and integrated policies are $\$ 96,784.60 /$ year and $\$ 95,998.58 /$ year, respectively. Therefore, the integrated policy gives total cost saving of $\$ 786.03 /$ year or $0.81 \%$. The second model has a similar discussion with cost saving in the amount of $0.24 \%$.

Table 4

The comparison of independent and integrated policies for model 1 and model 2

\begin{tabular}{|c|c|c|c|c|}
\hline & \multicolumn{2}{|l|}{ Model 1} & \multicolumn{2}{|l|}{ Model 2} \\
\hline & Independent & Integrated & Independent & Integrated \\
\hline Order quantity (units) & 586.52 & 677.67 & 409.23 & 438.05 \\
\hline Actual weight (lbs) & $12,903.51$ & $14,908.77$ & $9,003.04$ & $9,637.17$ \\
\hline Safety factor & 2.31 & 2.25 & 2.44 & 2.42 \\
\hline Number of delivery & 3 & 3 & 4 & 4 \\
\hline Total transport emission quantity (ton $\mathrm{CO}_{2}$ ) & 32.66 & 37.67 & 22.91 & 24.50 \\
\hline Total industrial emission quantity (ton $\mathrm{CO}_{2}$ ) & 104.46 & 107.10 & 103.27 & 104.39 \\
\hline Total emission (ton $\mathrm{CO}_{2}$ ) & 137.12 & 144.77 & 126.19 & 128.88 \\
\hline Total cost of buyer (\$/year) & $44,949.96$ & $45,222.49$ & $37,368.00$ & $37,454.28$ \\
\hline Total cost of manufacturer (\$/year) & $51,834.64$ & $50,776.08$ & $55,441.04$ & $55,132.63$ \\
\hline Total cost (\$/year) & $96,784.60$ & $95,998.58$ & $92,809.03$ & $92,586.91$ \\
\hline a) Saving of total emission [ton $\mathrm{CO}_{2},(\%)$ ] & & $-7.66 ;(-5.58 \%)$ & & $-2.7 ;(-2.14 \%)$ \\
\hline${ }^{b)}$ Saving of total cost [\$/year, $\left.(\%)\right]$ & & $786.03 ;(0.81 \%)$ & & $222.13 ;(0.24 \%)$ \\
\hline
\end{tabular}

a) $\left(T E_{\text {ind }}-T E_{\text {int }}\right) / T E_{\text {ind }} \times 100 \% \quad$ b) $\left(T C_{\text {ind }}-J T C\right) / T C_{\text {ind }} \times 100 \%$

In the next case, we included the freight schedule data and illustrated the above solution procedure. Table 5 presents the actual freight rate schedule data by considering shipping weight and distance. The data were adopted from Swenseth and Godfrey (2002) and Leaveano (2014b). The freight rates were redefined from the freight rate per pound to freight rate per pound per mile. For instance, we assume FTL can be delivered 600 miles with weight equal and more than 18,257 lbs and freight cost is a constant charge $(\$ 1,110 /$ shipment $)$. Therefore, the freight rate per pound per mile is obtained by dividing freight rate per shipment with the highest break point and distance. Unlike the case of 10,000-18,000 lbs, the freight rate per pound is a variable rate based on the load transported by the LTL. The freight rate per pound per mile can be obtained by dividing freight rate per pound with distance.

Table 5

The freight rate schedule data

\begin{tabular}{lll}
\hline Weight break & $F_{x} / \mathrm{lb}$ & $F_{x} / \mathrm{lb} /$ mile \\
\hline $1-227 \mathrm{lb}^{*}$ & $\$ 40$ & $\$ 0.000293685$ \\
$228-420 \mathrm{lb}$ & $\$ 0.176 / \mathrm{lb}$ & $\$ 0.000293333$ \\
$421-499 \mathrm{lb}^{*}$ & $\$ 74$ & $\$ 0.000247161$ \\
$500-932 \mathrm{lb}$ & $\$ 0.148 / \mathrm{lb}$ & $\$ 0.000246666$ \\
$933-999 \mathrm{lb}^{*}$ & $\$ 138$ & $\$ 0.000230230$ \\
$1,000-1,855 \mathrm{lb}$ & $\$ 0.138 / \mathrm{lb}$ & $\$ 0.000230000$ \\
$1,856-1,999 \mathrm{lb}^{*}$ & $\$ 256$ & $\$ 0.000213440$ \\
$2,000-4,749 \mathrm{lb}$ & $\$ 0.128 / \mathrm{lb}$ & $\$ 0.000213333$ \\
$4,750-9,999 \mathrm{lb}^{*}$ & $\$ 608$ & $\$ 0.000101343$ \\
$10,000-18,256 \mathrm{lb}$ & $\$ 0.0608 / \mathrm{lb}$ & $\$ 0.000101333$ \\
$18,257-$ more $^{*}$ & $\$ 1,110$ & $\$ 0.000040217$ \\
\hline
\end{tabular}

*) the fixed logistic rate 
We discussed the effect of various full truckload capacities $\left(W_{x}\right)$ from 25,$000 ; 20,000,15,000 ; 10,000$; 7,500 and 5,000 lbs. The results for this example are summarized in Table 6. The results obtained for various values of the full truckload capacity are lower total emission, especially emission from the transport sector. However, the opposite effect on the total cost will increase. The increase in the total costs is due to an increase in the manufacturer's setup and emission. If the full truckload capacity is decreased gradually then it will give an opportunity for the manufacturer to increase its production setup. For instance on the 2nd model, $W_{x}=7,500$ and 5,000 lbs, the results $n^{*}=5$ times and 8 times, respectively. Hence, the impact is the manufacturer's emission also increased (103.93 to 105.02 ton $\left.\mathrm{CO}_{2}\right)$. Because the emission has exceeded from $E L V_{I}$, then the penalty will be given to the manufacturer.

Table 6

The resulted and compared of $W_{x}=25,000 ; 20,000 ; 15,000 ; 10,000 ; 7,500 ;$ and $5,000 \mathrm{lbs}$

\begin{tabular}{|c|c|c|c|c|}
\hline & \multicolumn{2}{|c|}{$W_{x}=25,000 \mathrm{lbs}$} & \multicolumn{2}{|c|}{$W_{x}=20,000 \mathrm{lbs}$} \\
\hline & Model 1 & Model 2 & Model 1 & Model 2 \\
\hline Order quantity (units) & 668.77 & 431.06 & 666.64 & 429.38 \\
\hline Actual weight (lbs) & $14,713.04$ & $9,483.35$ & $14,666.05$ & $9,446.36$ \\
\hline Safety factor & 2.26 & 2.42 & 2.26 & 2.42 \\
\hline Number of delivery & 3 & 4 & 3 & 4 \\
\hline Total transport emission quantity (ton $\mathrm{CO}_{2}$ ) & 37.19 & 24.11 & 37.07 & 24.02 \\
\hline Total industrial emission quantity (ton $\mathrm{CO}_{2}$ ) & 106.84 & 104.12 & 106.78 & 104.05 \\
\hline Total emission (ton $\mathrm{CO}_{2}$ ) & 144.03 & 128.23 & 143.85 & 128.07 \\
\hline Total cost of buyer ( $\$ /$ year) & $44,180.69$ & $35,875.94$ & $43,929.21$ & $35,493.95$ \\
\hline Total cost of manufacturer (\$/year) & $50,830.32$ & $55,181.02$ & $50,844.73$ & $55,195.06$ \\
\hline Total cost (\$/year) & $95,011.01$ & $91,056.96$ & $94,773.94$ & $90,689.01$ \\
\hline a) Saving of total emission [ton $\mathrm{CO}_{2},(\%)$ ] & & $15.8 ;(10.97 \%)$ & & $15.78 ;(10.97 \%)$ \\
\hline \multirow{3}{*}{${ }^{b)}$ Saving of total cost $[\$ /$ year, $(\%)]$} & & $3,954.06 ;(4.16 \%)$ & & $4,084.93 ;(4.31 \%)$ \\
\hline & \multicolumn{2}{|c|}{$W_{x}=15,000 \mathrm{lbs}$} & \multicolumn{2}{|c|}{$W_{x}=10,000 \mathrm{lbs}$} \\
\hline & Model 1 & Model 2 & Model 1 & Model 2 \\
\hline Order quantity (units) & 674.21 & 435.33 & 454.55 & 431.13 \\
\hline Actual weight (lbs) & $14,832.60$ & $9,577.37$ & $10,000.00$ & $9,484.80$ \\
\hline Safety factor & 2.26 & 2.42 & 2.40 & 2.42 \\
\hline Number of delivery & 3 & 4 & 4 & 4 \\
\hline Total transport emission quantity (ton $\mathrm{CO}_{2}$ ) & 37.48 & 24.35 & 25.40 & 24.12 \\
\hline Total industrial emission quantity (ton $\mathrm{CO}_{2}$ ) & 107.00 & 104.28 & 105.02 & 104.12 \\
\hline Total emission (ton $\mathrm{CO}_{2}$ ) & 144.48 & 128.63 & 130.43 & 128.24 \\
\hline Total cost of buyer ( $\$$ year) & $53,171.58$ & $45,195.90$ & $52,704.96$ & $44,244.31$ \\
\hline Total cost of manufacturer (\$/year) & $50,796.09$ & $55,149.55$ & $52,943.57$ & $55,180.48$ \\
\hline Total cost $(\$ /$ year $)$ & $103,967.67$ & $100,345.45$ & $105,648.53$ & $99,424.80$ \\
\hline a) Saving of total emission [ton $\left.\mathrm{CO}_{2},(\%)\right]$ & & $15.86 ;(10.97 \%)$ & & $2.2 ;(1.68 \%)$ \\
\hline \multirow[t]{3}{*}{${ }^{b)}$ Saving of total cost $[\$ /$ year, $(\%)]$} & & $3,622.22 ;(3.48 \%)$ & & $6,223.74 ;(5.89 \%)$ \\
\hline & \multicolumn{2}{|c|}{$W_{x}=7,500 \mathrm{lbs}$} & \multicolumn{2}{|c|}{$W_{x}=5,000 \mathrm{lbs}$} \\
\hline & Model 1 & Model 2 & Model 1 & Model 2 \\
\hline Order quantity (units) & 340.91 & 340.91 & 227.27 & 227.27 \\
\hline Actual weight (lbs) & $7,500.00$ & $7,500.00$ & $5,000.00$ & $5,000.00$ \\
\hline Safety factor & 2.51 & 2.51 & 2.65 & 2.65 \\
\hline Number of delivery & 6 & 5 & 9 & 8 \\
\hline Total transport emission quantity (ton $\mathrm{CO}_{2}$ ) & 19.15 & 19.15 & 12.90 & 12.90 \\
\hline Total industrial emission quantity (ton $\mathrm{CO}_{2}$ ) & 107.22 & 103.93 & 107.22 & 105.02 \\
\hline Total emission (ton $\mathrm{CO}_{2}$ ) & 126.37 & 123.08 & 120.12 & 117.93 \\
\hline Total cost of buyer ( $\$ /$ year) & $54,711.70$ & $43,828.47$ & $61,226.03$ & $47,686.54$ \\
\hline Total cost of manufacturer (\$/year) & $53,992.56$ & $56,034.52$ & $55,072.11$ & $57,237.92$ \\
\hline Total cost $(\$ /$ year $)$ & $108,704.27$ & $99,862.98$ & $116,298.14$ & $104,924.47$ \\
\hline a) Saving of total emission [ton $\left.\mathrm{CO}_{2},(\%)\right]$ & & $3.29 ;(2.6 \%)$ & & $2.2 ;(1.83 \%)$ \\
\hline b) Saving of total cost $[\$ /$ year, $(\%)]$ & & $8,841.29 ;(8.13 \%)$ & & $11,373.68 ;(9.78 \%)$ \\
\hline
\end{tabular}

a) $\left(T E_{1}-T E_{2}\right) / T E_{1} \times 100 \%$

b) $\left(J T C_{1}-J T C_{2}\right) / J T C_{1} \times 100 \%$

\section{Analysis and discussion}

In this section, we studied and analyzed the effect of various parameters to determining the optimal decision variables such as the optimal order quantity, safety factor, the number of deliveries and total 
emission and subsequently on joint total cost for both models. The parameter dividing 3 categories, there are the general parameter, transport sector and industrial sector (Table 7).

\section{Table 7}

Categories of sensitivity parameter

\begin{tabular}{lll}
\hline General parameter & Transport sector & Industrial sector \\
\hline 1. Penalty & 1. Fuel price & 1. Loss rate (\%) \\
2. Incentive & 2. Fuel consumption & 2. Indirect industry emission factor \\
3. Carbon emission tax & 3. Distance & 3. Direct industry emission factor \\
4. Emission limit value & 4. Indirect transport emission factor & \\
5. Production rate & 5. Direct transport emission factor & \\
6. Average of demand & & \\
7. Standard deviation of demand & & \\
\hline
\end{tabular}

\subsection{Sensitivity of general parameters}

\subsubsection{Effect of changing in the Government's penalties and incentives}

We analyzed the effect of changing in the penalty on total emissions and total costs. From the assumptions used in the development model that has been described earlier, the Government's penalty should be larger than the Government's incentive. We use incentive \$125/year/ton $\mathrm{CO}_{2}$. So, the penalties used in this analysis are $125,150,200,250,350,500,700,1000,1200$ and 1500 (\$/year/ton $\left.\mathrm{CO}_{2}\right)$. The effects of changing in the penalty on the decision variables and total costs are shown in Table 8 .

Table 8

The effect of changing in penalties and incentives on decision variables and total cost

\begin{tabular}{|c|c|c|c|c|c|c|c|c|c|c|c|c|}
\hline \multirow{2}{*}{ Penalty } & \multicolumn{3}{|c|}{ Model 1} & & & \multicolumn{4}{|c|}{ Model 2} & & \multicolumn{2}{|l|}{ Saving } \\
\hline & $Q_{1}{ }^{*}$ & $k_{1}{ }^{*}$ & $n$ & $T E_{1}{ }^{*}$ & $J T C_{1}$ & $Q_{2}{ }^{*}$ & $k_{2}{ }^{*}$ & $n_{2}{ }^{*}$ & $T E_{2}{ }^{*}$ & $J T C_{2}$ & $T E^{\text {a) }}$ & $J T C^{\text {b) }}$ \\
\hline 125 & 677.67 & 2.25 & 3 & 144.77 & $95,998.58$ & 577.24 & 2.31 & 3 & 136.34 & $94,863.29$ & $8.44(5.82 \%)$ & $1,135.3(1.18 \%)$ \\
\hline 150 & 677.67 & 2.25 & 3 & 144.77 & $95,998.58$ & 569.47 & 2.32 & 3 & 135.69 & $94,644.58$ & $9.09(6.27 \%)$ & $1,354(1.41 \%)$ \\
\hline 200 & 677.67 & 2.25 & 3 & 144.77 & $95,998.58$ & 458.08 & 2.40 & 4 & 130.76 & $94,082.97$ & $14.02(9.68 \%)$ & $1,915.61(2 \%)$ \\
\hline 250 & 677.67 & 2.25 & 3 & 144.77 & $95,998.58$ & 447.73 & 2.41 & 4 & 129.79 & $93,358.36$ & $14.99(10.35 \%)$ & $2,640.22(2.75 \%)$ \\
\hline 350 & 677.67 & 2.25 & 3 & 144.77 & $95,998.58$ & 428.97 & 2.42 & 4 & 128.03 & $91,771.59$ & $16.74(11.56 \%)$ & $4,227(4.4 \%)$ \\
\hline 500 & 677.67 & 2.25 & 3 & 144.77 & $95,998.58$ & 404.79 & 2.44 & 4 & 125.77 & $89,087.84$ & $19.01(13.13 \%)$ & $6,910.74(7.2 \%)$ \\
\hline 700 & 677.67 & 2.25 & 3 & 144.77 & $95,998.58$ & 378.10 & 2.47 & 4 & 123.27 & $85,031.39$ & $21.51(14.85 \%)$ & $10,967.19(11.42 \%)$ \\
\hline 1000 & 677.67 & 2.25 & 3 & 144.77 & $95,998.58$ & 302.58 & 2.55 & 5 & 119.12 & $77,987.52$ & $25.65(17.72 \%)$ & $18,011.06(18.76 \%)$ \\
\hline 1200 & 677.67 & 2.25 & 3 & 144.77 & $95,998.58$ & 288.07 & 2.56 & 5 & 117.62 & $72,706.51$ & $27.15(18.75 \%)$ & $23,292.07(24.26 \%)$ \\
\hline 1500 & 677.67 & 2.25 & 3 & 144.77 & $95,998.58$ & 269.74 & 2.59 & 5 & 115.73 & $64,272.62$ & $29.04(20.06 \%)$ & $31,725.96(33.05 \%)$ \\
\hline \multirow{2}{*}{$\begin{array}{l}\text { Incen- } \\
\text { tive }\end{array}$} & \multicolumn{5}{|l|}{ Model 1} & \multicolumn{5}{|c|}{ Model 2} & \multicolumn{2}{|c|}{ Saving } \\
\hline & $Q_{1}{ }^{*}$ & $k_{1}{ }^{*}$ & $n$ & $T E_{1}{ }^{*}$ & $J T C_{1}$ & $Q_{2}{ }^{*}$ & $k_{2}{ }^{*}$ & $n_{2}{ }^{*}$ & $T E_{2}{ }^{*}$ & $J T C_{2}$ & $T E^{\text {a) }}$ & $J T C^{\text {b) }}$ \\
\hline 5 & 677.67 & 2.25 & 3 & 144.77 & $95,998.58$ & 462.43 & 2.40 & 4 & 131.17 & $94,358.97$ & $13.61(9.4 \%)$ & $1,639.61(1.71 \%)$ \\
\hline 10 & 677.67 & 2.25 & 3 & 144.77 & $95,998.58$ & 461.33 & 2.40 & 4 & 131.06 & $94,290.74$ & $13.71(9.47 \%)$ & $1,707.85(1.78 \%)$ \\
\hline 15 & 677.67 & 2.25 & 3 & 144.77 & $95,998.58$ & 460.24 & 2.40 & 4 & 130.96 & $94,221.99$ & $13.82(9.54 \%)$ & $1,776.59(1.85 \%)$ \\
\hline 25 & 677.67 & 2.25 & 3 & 144.77 & $95,998.58$ & 458.08 & 2.40 & 4 & 130.76 & $94,082.97$ & $14.02(9.68 \%)$ & $1,915.61(2 \%)$ \\
\hline 50 & 677.67 & 2.25 & 3 & 144.77 & $95,998.58$ & 452.82 & 2.40 & 4 & 130.27 & $93,726.72$ & $14.51(10.02 \%)$ & $2,271.86(2.37 \%)$ \\
\hline 75 & 677.67 & 2.25 & 3 & 144.77 & $95,998.58$ & 447.73 & 2.41 & 4 & 129.79 & $93,358.36$ & $14.99(10.35 \%)$ & $2,640.22(2.75 \%)$ \\
\hline 100 & 677.67 & 2.25 & 3 & 144.77 & $95,998.58$ & 442.81 & 2.41 & 4 & 129.33 & $92,978.30$ & $15.45(10.67 \%)$ & $3,020.29(3.15 \%)$ \\
\hline 125 & 677.67 & 2.25 & 3 & 144.77 & $95,998.58$ & 438.05 & 2.42 & 4 & 128.88 & $92,586.91$ & $15.89(10.97 \%)$ & $3,411.67(3.55 \%)$ \\
\hline 250 & 677.67 & 2.25 & 3 & 144.77 & $95,998.58$ & 416.36 & 2.43 & 4 & 126.85 & $90,472.12$ & $17.92(12.38 \%)$ & $5,526.47(5.76 \%)$ \\
\hline 300 & 677.67 & 2.25 & 3 & 144.77 & $95,998.58$ & 408.54 & 2.44 & 4 & 126.12 & $89,558.24$ & $18.66(12.88 \%)$ & $6,440.34(6.71 \%)$ \\
\hline
\end{tabular}

a) $\left(T E_{1}-T E_{2}\right) / T E_{1} \times 100 \% \quad$ b) $\left(J T C_{1}-J T C_{2}\right) / J T C_{1} \times 100 \%$ 


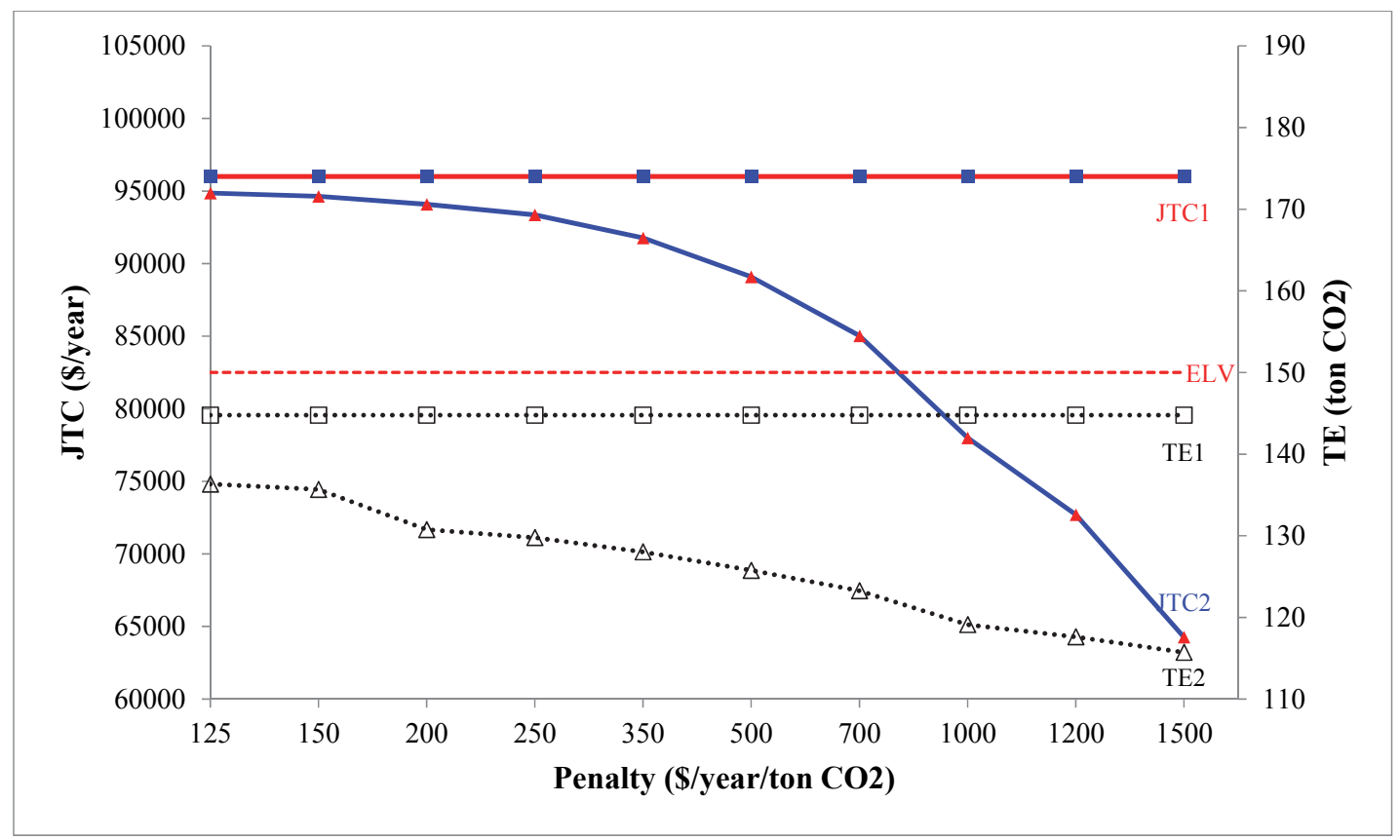

Fig. 4. The effect of changing in penalty on total cost and total emission

In Fig. 4, it can be observed that the penalty policy can reduce total emission and total cost on the second model. As we know, the first model is not considered as the penalty policy; hence the results show that the total emission and total cost are the constant rates. The comparison of these models produces total emission saving from $5 \%$ to $20 \%$ and total cost saving from $1 \%$ to $33 \%$. So, we conclude that the Government's penalty will give impact on the reduction in total emission and total cost of the parties.

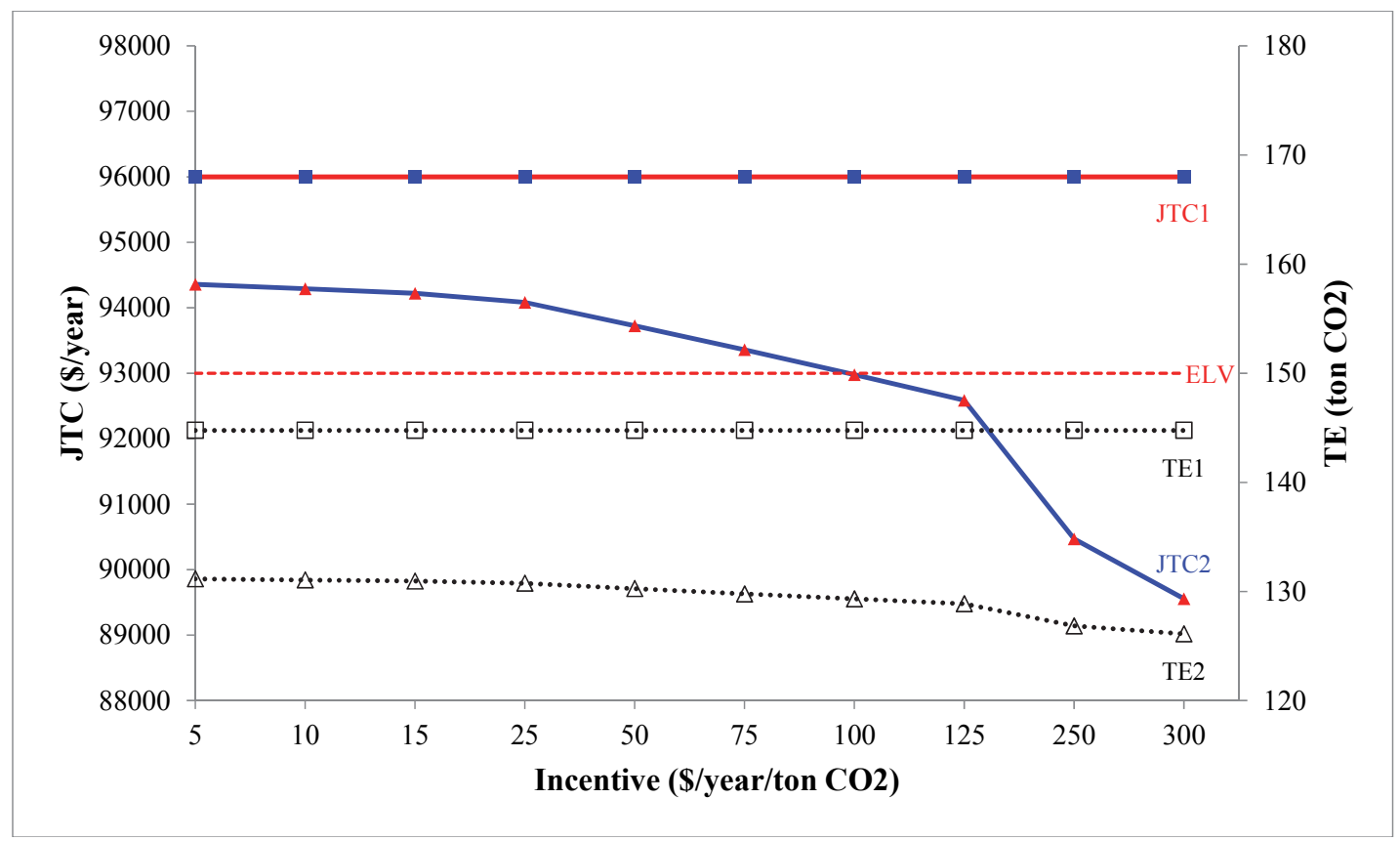

Fig. 5. The effect of changing in incentive on total cost and total GHG emission 
Table 8 shows the effect of varying the incentives to determine the decision variables and total costs. In contrast to the penalty policy, the incentive should be lower than the penalty. The penalty, in this case, is $\$ 300 /$ year/ton $\mathrm{CO}_{2}$. Hence, the incentives used in this analysis are 5, 10, to 300. Fig. 5 shows that the second model produces the total emission, and the total cost is lower than without penalty and incentive policies. Thus, we conclude with the same penalty conclusion that the Government's incentive can reduce the total emission and the total cost with saving on total emission and total cost of $9 \%-13 \%$ and $1 \%$ $6 \%$, respectively.

\subsubsection{Effect of changing in carbon emission tax}

Carbon emission tax has an impact to determining the amount of transport and industrial emissions and total costs on both the models. The parties will pay a carbon emission tax $\left(\$ /\right.$ ton $\left.\mathrm{CO}_{2}\right)$ on how much GHG emission produced by transport and industrial sectors. In this case, we used the initially of a carbon tax of $\$ 20 /$ ton $\mathrm{CO}_{2}$ and total $E L V$ of 150 ton $\mathrm{CO}_{2}\left(E L V_{\mathrm{I}}=100\right.$ ton $\mathrm{CO}_{2}$ and $E L V_{\mathrm{T}}=50$ ton $\left.\mathrm{CO}_{2}\right)$. The behavior of the total emission and total cost for both models is shown in Figure 6. In this experiment, the carbon tax is associated with the optimal order quantity, and it affects the total cost and total emission. In the case when carbon taxes are more $\$ 20 /$ ton $\mathrm{CO}_{2}$, the impact is the increase in the total emission and total cost, simultaneously. The carbon tax is $\$ 55 /$ ton $\mathrm{CO}_{2}$ will cause the second model to be inefficient compared to the first model. Furthermore, the increase in carbon tax also leads to a large gap of the total emission between the first and second model (saving of $11 \%$ - 17\%). It is affected by penalty and incentive imposed on the second model. Finally, we noted that the carbon emission tax influences the total emission and total cost.

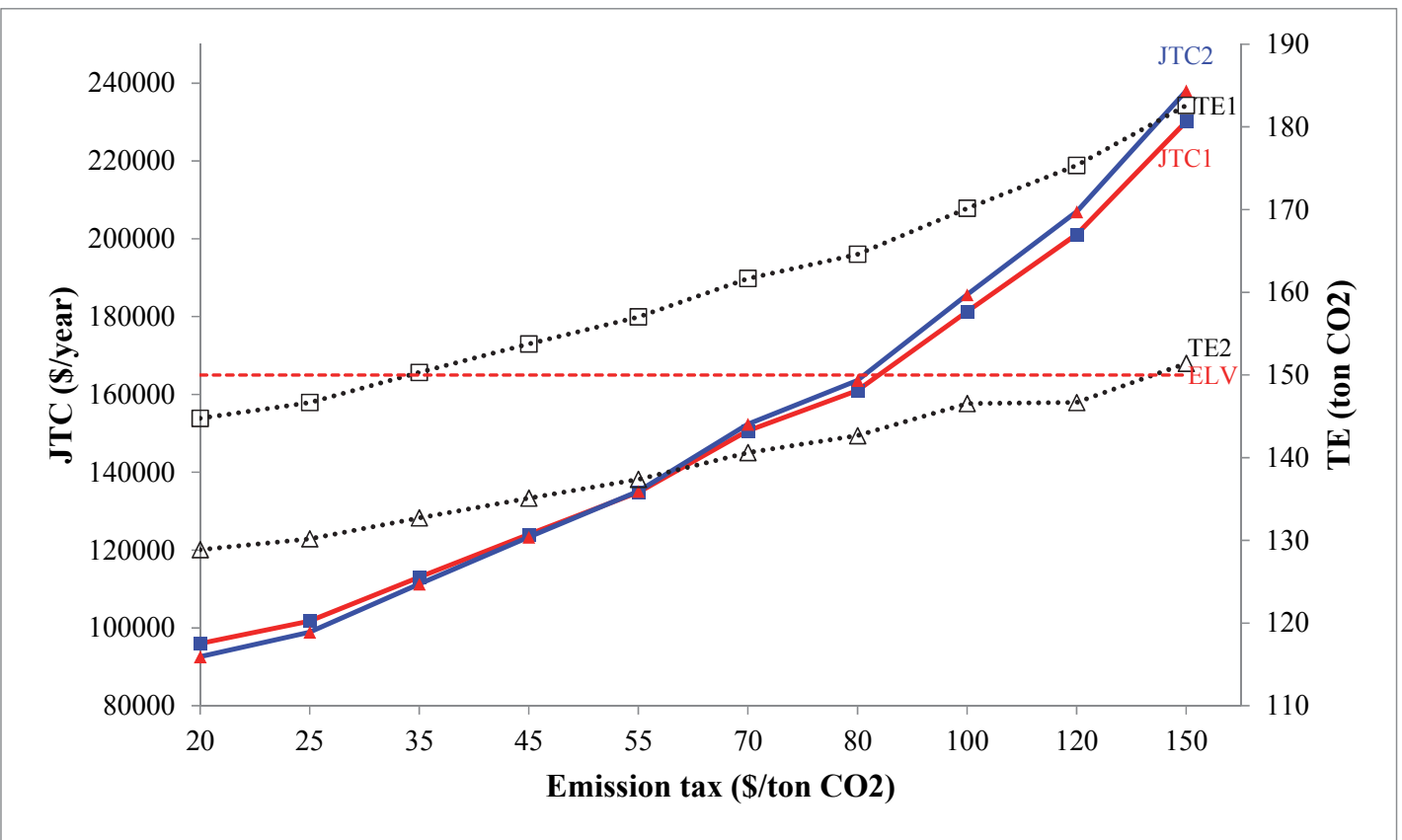

Fig. 6. The effect of changing in carbon emission tax on total cost and total GHG emission

\subsubsection{Effect of changing in Emission Limit Value}

Here, we studied the effect of varying $E L V$ from transport and industry sectors. In this case, we set total $E L V$ by 150 ton $\mathrm{CO}_{2}$. The values of $E L V$ transport start from 10 to 100 ton $\mathrm{CO}_{2}$ (low to high) and contrary to the values of $E L V$ industry start from 140 to 50 ton $\mathrm{CO}_{2}$ (high to low). Figure 7 portrays a simple relationship between total cost and two $E L V \mathrm{~s}$. Based on the $E L V$ transport low value and the $E L V$ industry high value, the impact is the total cost of the buyer and the manufacturer will be increased and decreased, respectively. However, for a high value of $E L V$ transport and low value of $E L V$ industry, the impact is the total cost of the buyer and the manufacturer will be decreased and increased, respectively. There is a 
cutting point representing the trade-off among total cost of the buyer and the manufacturer and the values of $E L V$.

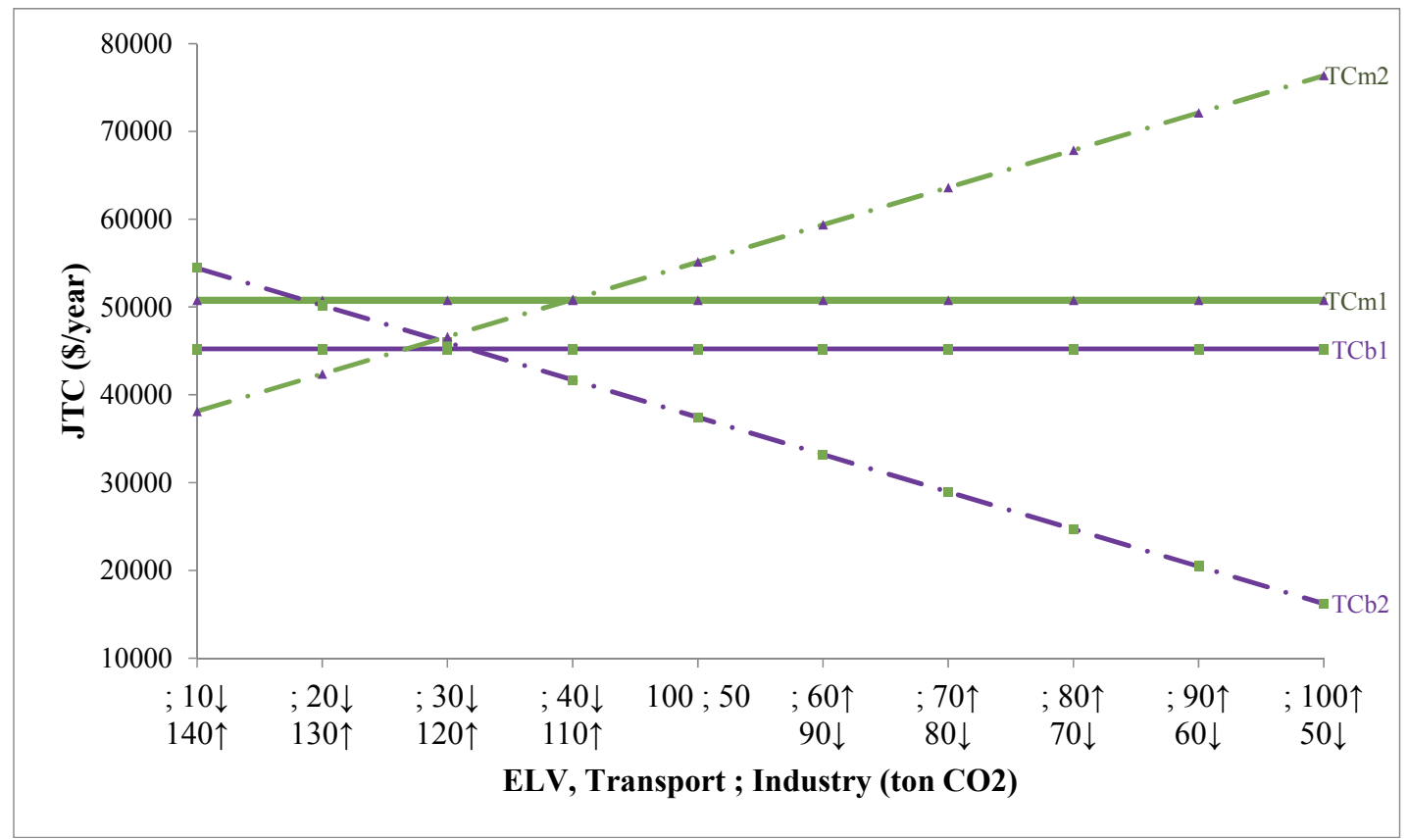

Fig. 7. The effect of changing in ELV on total cost and total emission

\subsubsection{Effect of changing in production rate}

In this example, we discussed and investigated the varying values of production rate. As shown in Figure 8 , the increase in production rate will make the total cost of the both models increase. Likewise, the total emission will also increase. The increase in the total emission is influenced by a large increase in the transport emission while the industrial emission declines. It affects to an increase in the buyer's holding cost, carbon emission cost, and penalty, but the manufacturer's holding cost and carbon emission cost and penalty will be decreased.

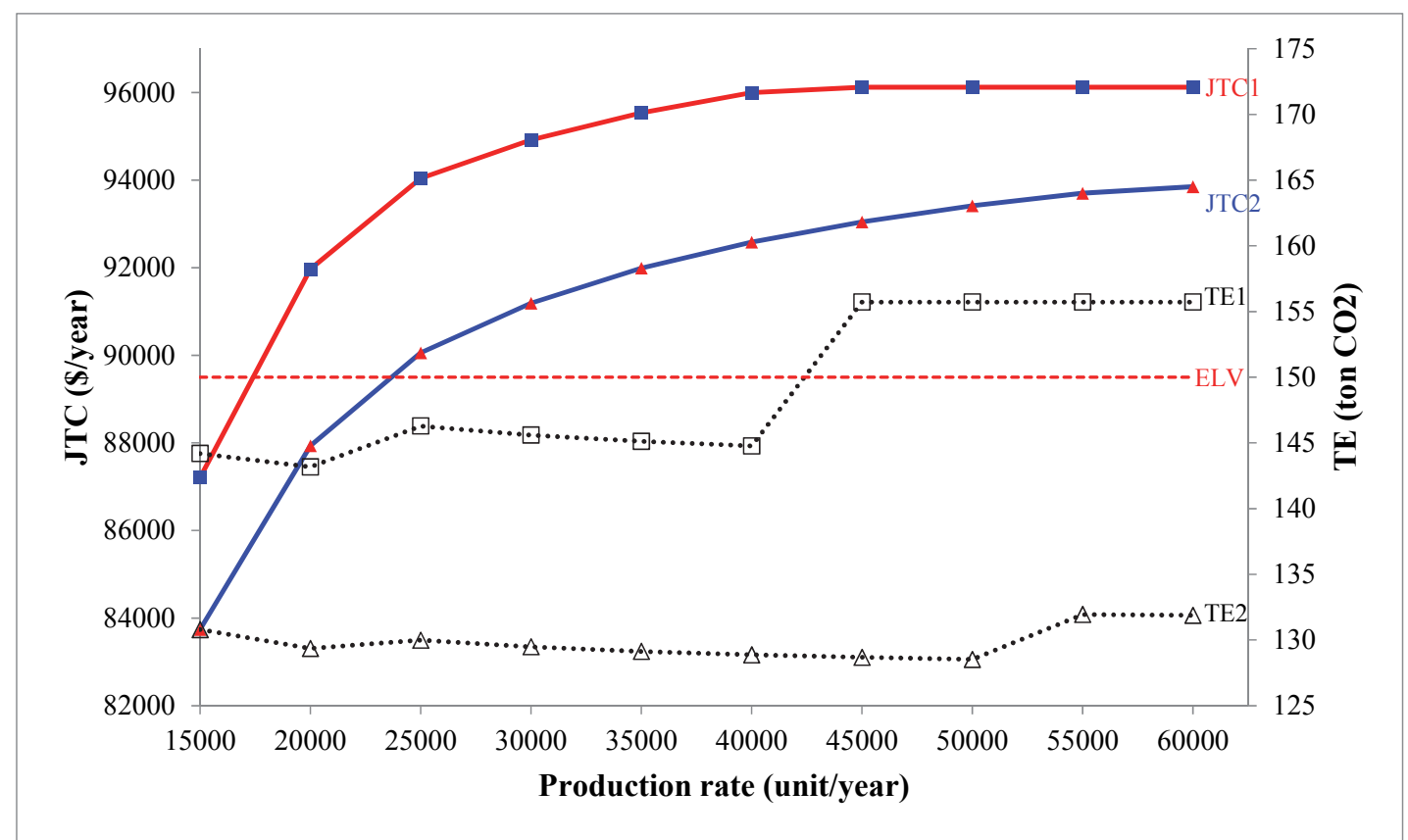

Fig. 8. The effect of changing in production rate on total cost and total emission 


\subsubsection{Effect of changing in average and standard deviation of demand}

In the Fig. 9 and Fig. 10 show the behavior of the stochastic environment. We may see that if the average and standard deviation rises, then the total cost will also elevate in both models. If the demand average increase, the buyer's holding cost, carbon cost and safety stock on the both models will also increase. In contrast to demand standard deviation, having more demand standard deviation will affect to reduce the buyer's holding and carbon costs, and safety stock is pretty much to handle demand variation.

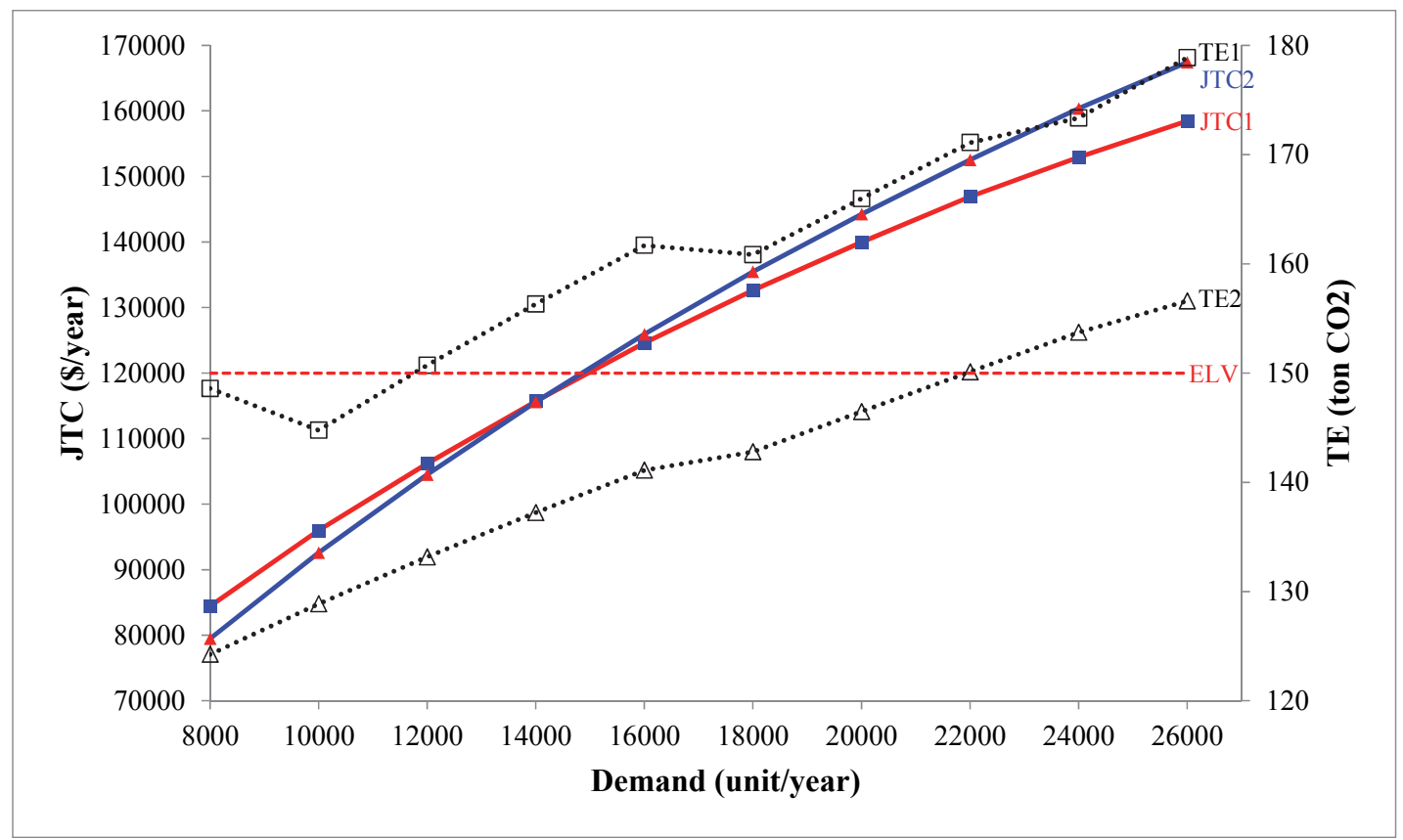

Fig. 9. Effect of changing in demand average on total cost and total emission

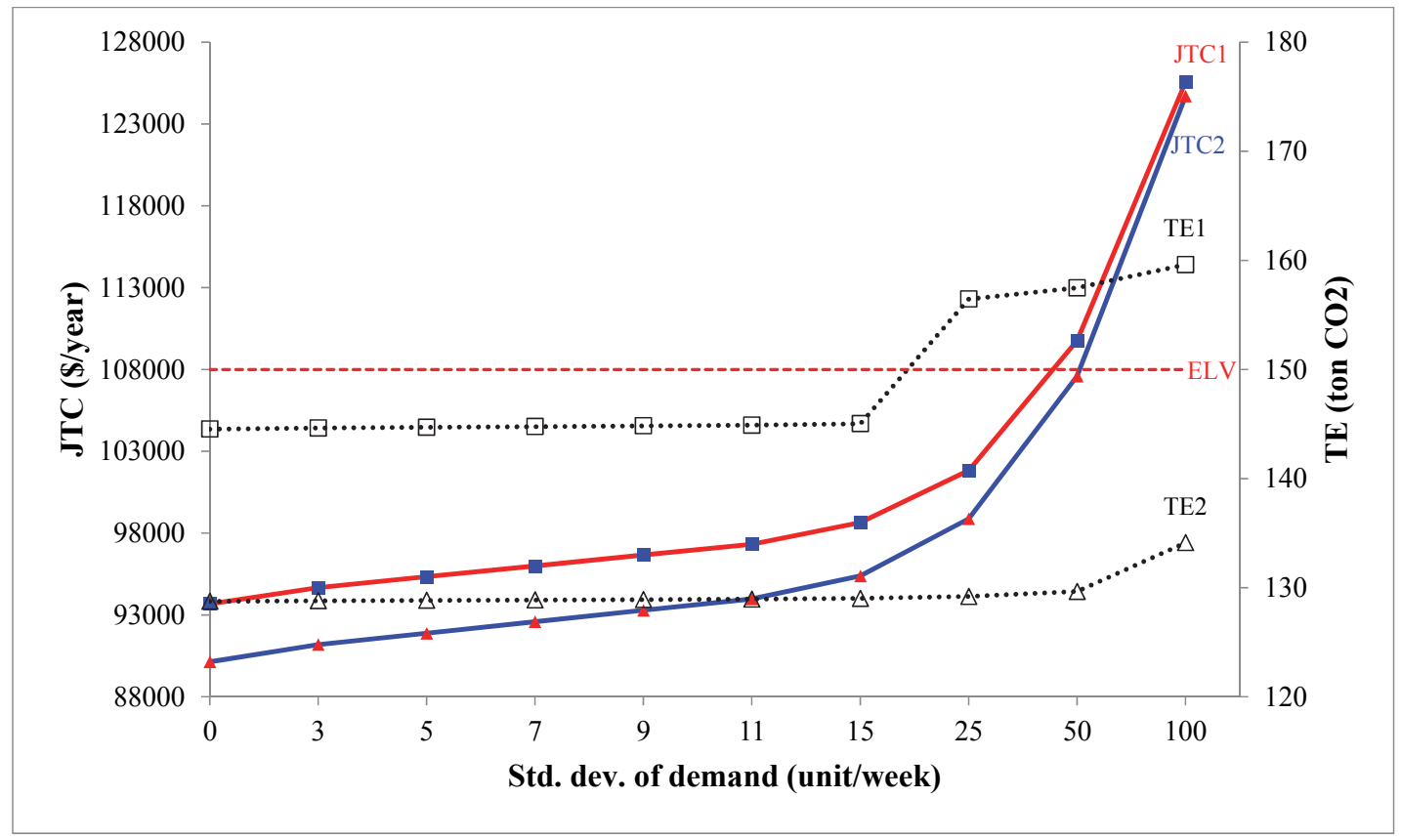

Fig. 10. Effect of changing in demand standard deviation on total cost and total emission 


\subsection{Sensitivity parameter from the transport sector}

Figs. (11-15) show the effect of varying parameters from the transport sector, such as fuel price and consumption, distances, transport direct and indirect factors on total emissions and total cost of a supply chain. In the second model, the penalty and incentive policies are considered. The graphs show that the cost can be significantly increased by distances and direct emission factor and the second model can reduce total cost and total emission. The increase in total cost comes from the buyer's cost, otherwise the manufacturer's cost.

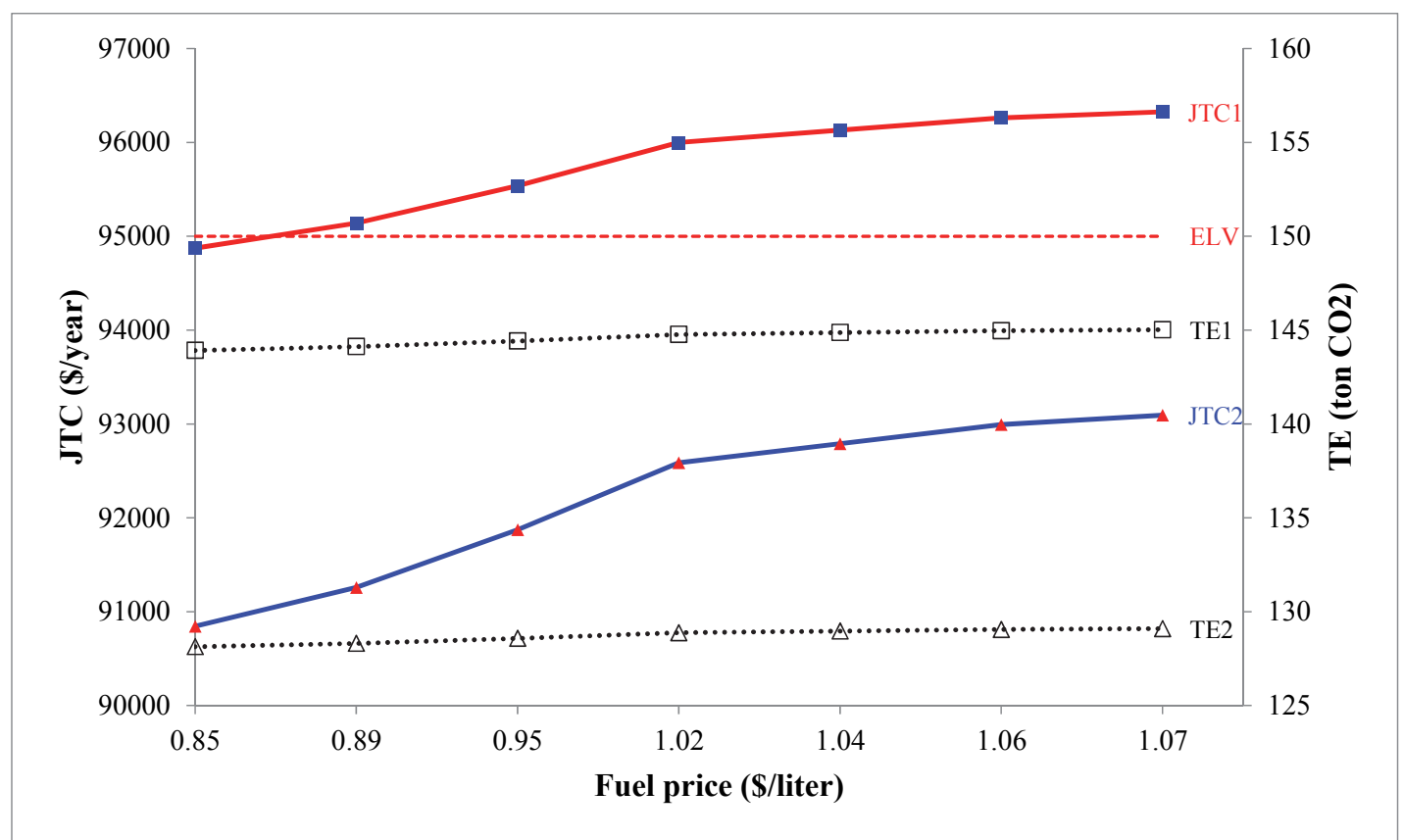

Fig. 11. Effect of changing in fuel price on total cost and emission

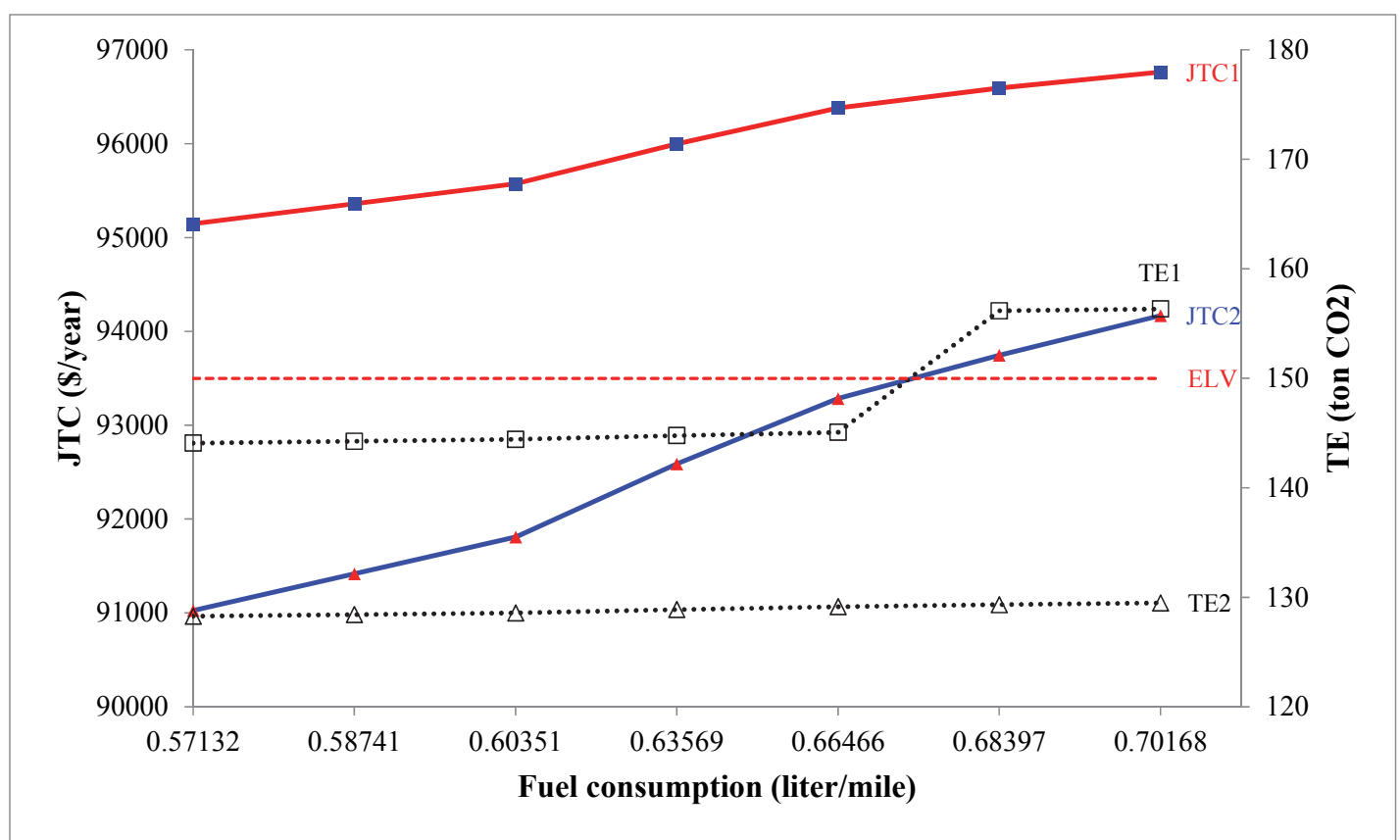

Fig. 12. Effect of changing in fuel consumption on total cost and total emission 


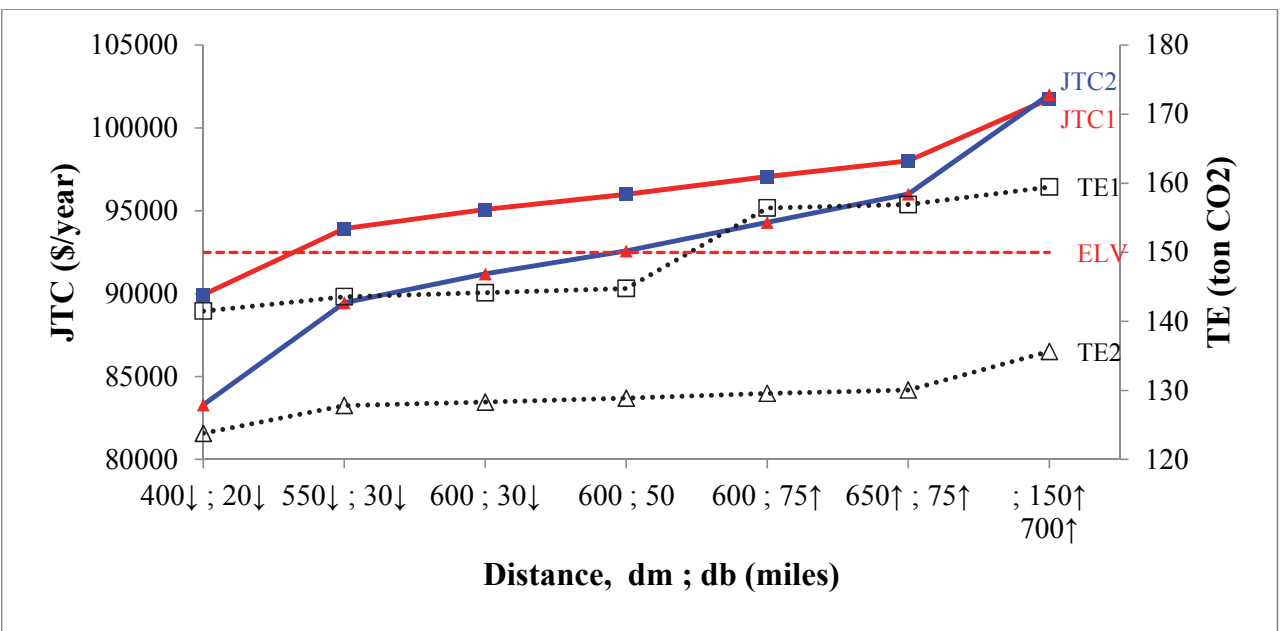

Fig. 13. Effect of changing in distance on total cost and total emission

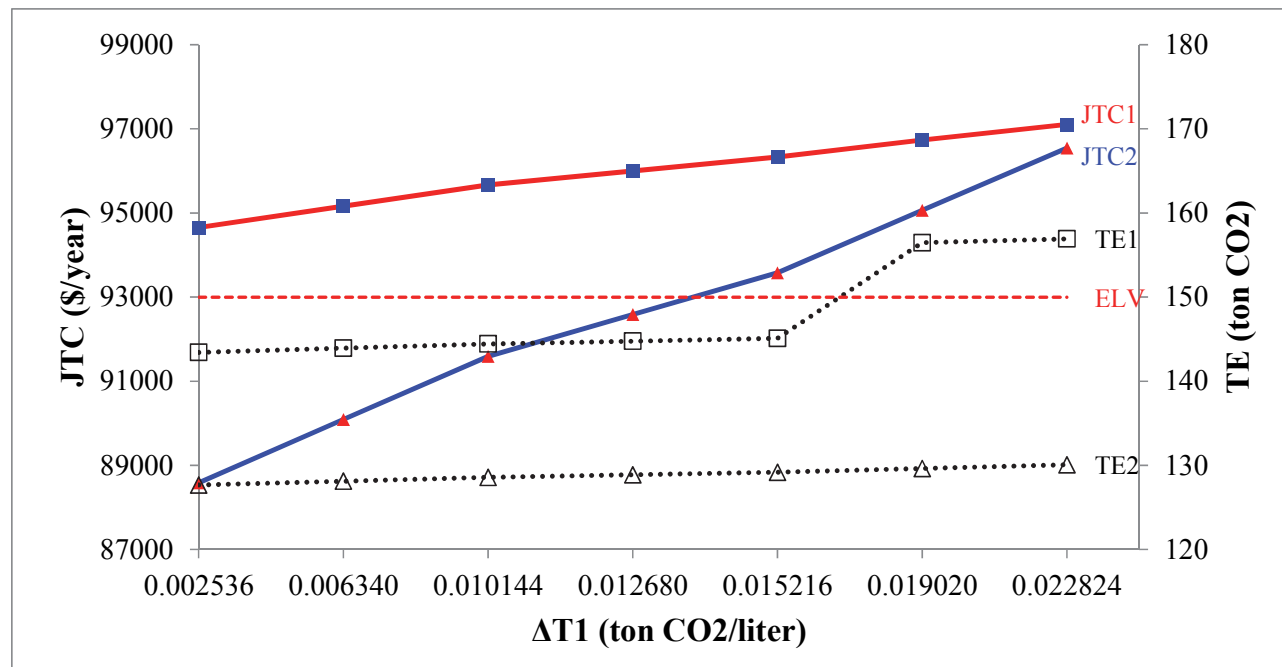

Fig. 14. Effect of changing in transport indirect emission factor on total cost and total emission

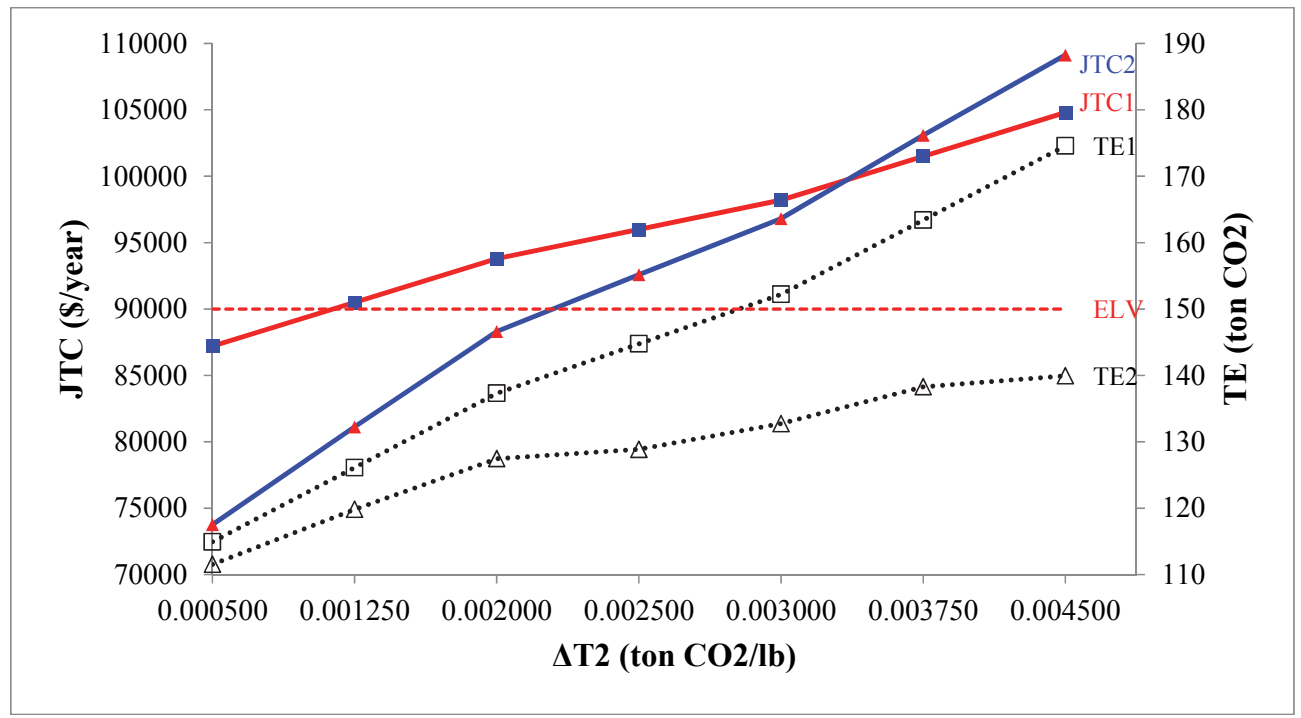

Fig. 15. Effect of changing in transport direct emission factor on total emission 


\subsection{Sensitivity parameter from the industry sector}

The observations of the varying parameter from industrial parameters, an especially loss rate of energy (electricity, steam, heating, and cooling), industrial indirect and direct emissions factors on total cost and total emission are illustrated in Figs. (16-18. In this case, the total cost is affected by the increase in the optimal production quantity and total industrial emission; hence the impacts on the total cost of the manufacturer are the manufacturer's holding cost, setup cost, carbon emission cost and penalty cost. As we can see, the total cost can be significantly increased by the industrial direct emission factor. Finally, we concluded that these parameters contributed to the increase in total emission and total cost.

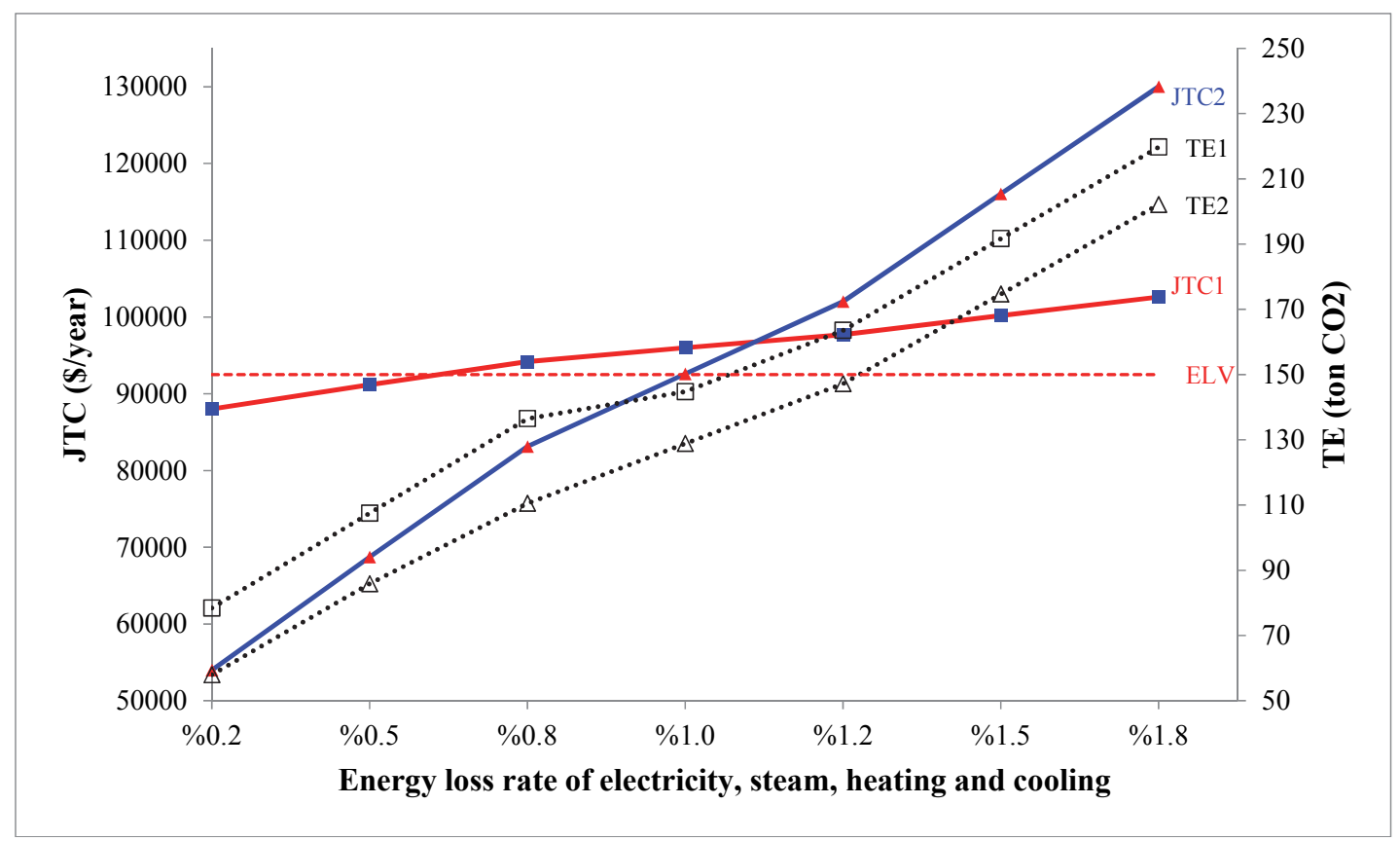

Fig. 16. Effect of changing in loss rate of electricity, steam, heating and cooling on total cost and total emission

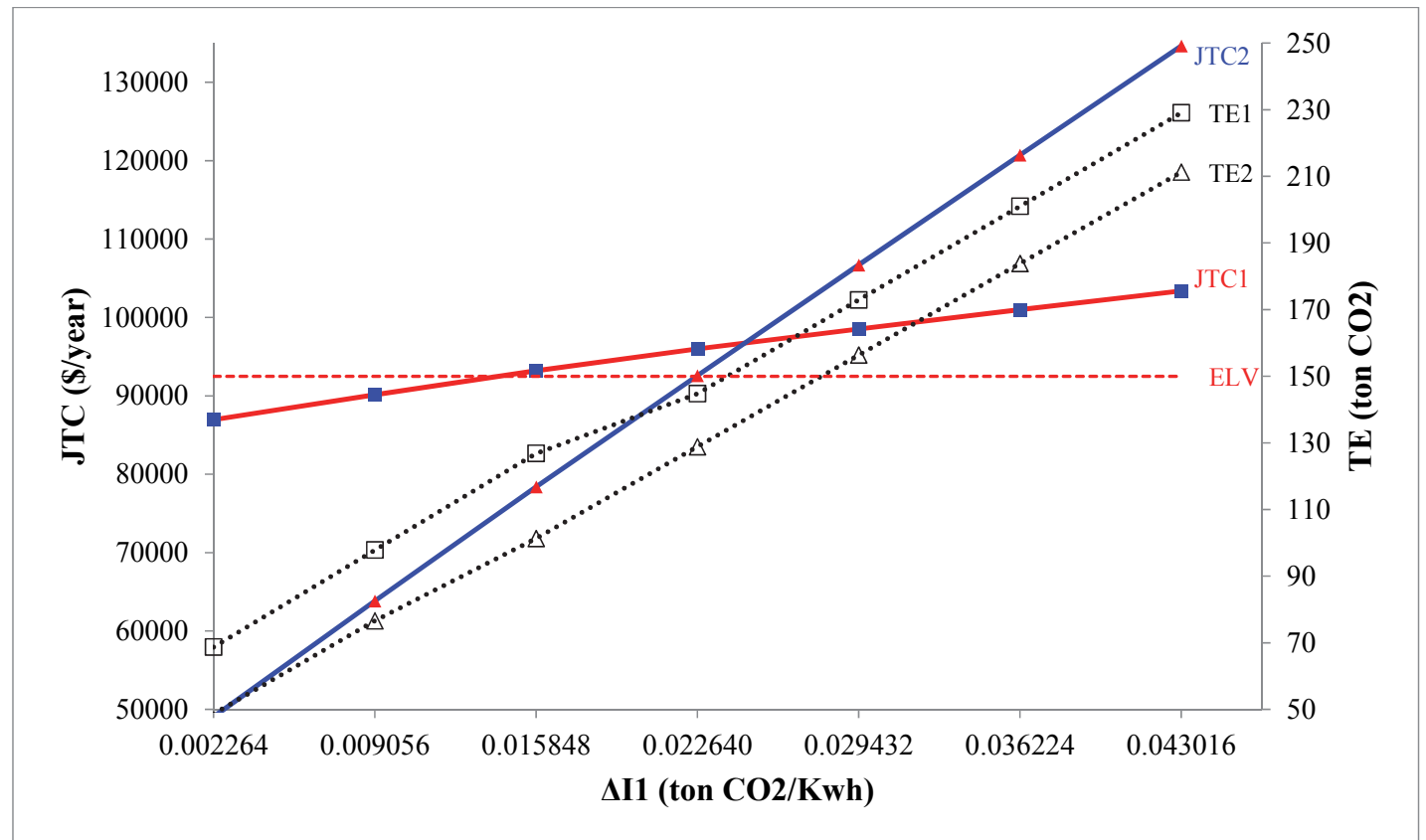

Fig. 17. Effect of changing in industrial indirect emission factor on total cost and total emission 


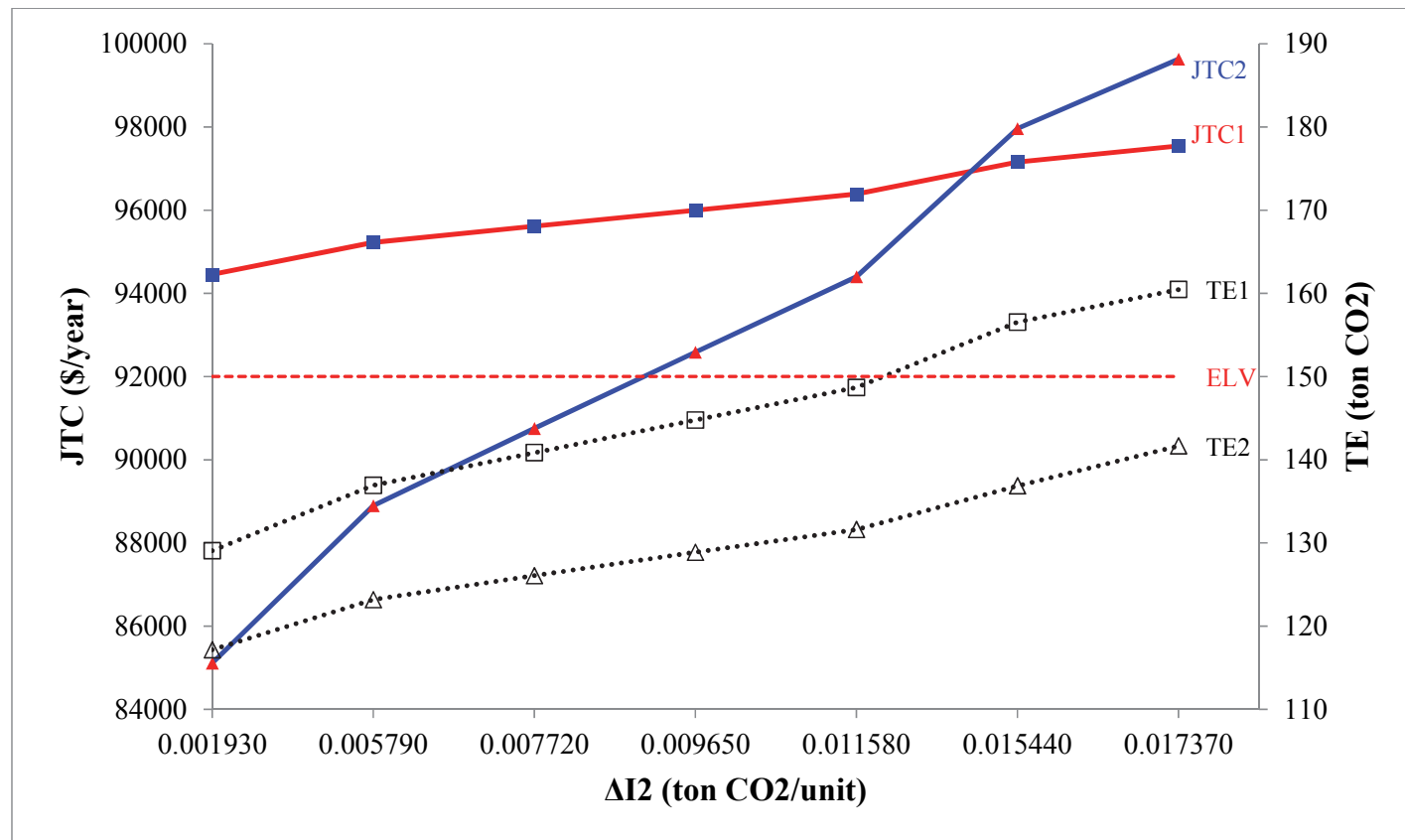

Fig. 18. Effect of changing in industrial direct emission factor on total cost and total emission

\section{Conclusion}

In this study, we formulated a supply chain inventory model considering carbon emission tax, the penalty and incentive policies. Here, we also considered stochastic demand and industrial and transport GHG emissions. The numerical example and analysis showed that these policies and stochastic environment can influence the decision-makers in determining the optimal order quantity and reduce total emission resulting from transport and industrial sectors. We also examined the relationship between relevant parameters of these sectors and the total emission associated with total cost. Significant cost savings on total cost of the entire supply chain can also be achieved by considering the penalty and incentive policies. Our findings provided some useful insights to practitioners. This paper contributed to an integrated inventory literature with GHG emission.

The proposed models have limitations. The proposed model in this paper could be extended in various directions. Future research may consider multi-manufacturer and multi-buyer. The other indirect emission may be involved such as waste disposal. In addition, other policies to reduce GHG emissions can be incorporated into inventory models such as investment cost of emission reductions, recycling, remanufacturing, cleaner production or green manufacturing etc.

\section{Acknowledgement}

The author greatly appreciates the anonymous referees for their valuable and helpful suggestions on earlier drafts of this paper.

\section{References}

Abad, P. L., \& Aggarwal, V. (2005). Incorporating transport cost in the lot size and pricing decisions with downward sloping demand. International Journal of Production Economics, 95(3), 297-305.

Banerjee, A. (1986). A joint economic-lot-size model for purchaser and vendor. Decision sciences, 17(3), 292-311.

Baumol, W. J., \& Vinod, H. D. (1970). An inventory theoretic model of freight transport demand. Management science, 16(7), 413-421. 
Bazan, E., Jaber, M. Y., \& Zanoni, S. (2015a). Supply chain models with greenhouse gases emissions, energy usage and different coordination decisions. Applied Mathematical Modelling, 39(17), 51315151.

Bazan, E., Jaber, M. Y., \& El Saadany, A. M. (2015b). Carbon emissions and energy effects on manufacturing-remanufacturing inventory models. Computers \& Industrial Engineering, 88, 307316.

Bazan, E., Jaber, M. Y., \& Zanoni, S. (2017). Carbon emissions and energy effects on a two-level manufacturer-retailer closed-loop supply chain model with remanufacturing subject to different coordination mechanisms. International Journal of Production Economics, 183, 394-408.

Ben-Daya, M., \& Hariga, M. (2004). Integrated single vendor single buyer model with stochastic demand and variable lead time. International Journal of Production Economics, 92(1), 75-80.

Ben-Daya, M., \& Raouf, A. (1994). Inventory models involving lead time as a decision variable. Journal of the Operational Research Society, 45(5), 579-582.

Ben-Daya, M., Darwish, M., \& Ertogral, K. (2008). The joint economic lot sizing problem: Review and extensions. European Journal of Operational Research, 185(2), 726-742.

Benjaafar, S., Li, Y., \& Daskin, M. (2012). Carbon footprint and the management of supply chains: Insights from simple models. IEEE transactions on automation science and engineering, 10(1), 99116.

Carter, J. R., \& Ferrin, B. G. (1996). Transportation costs and inventory management: Why transportation costs matter. Production and Inventory Management Journal, 37(3), 58.

Chen, X., Benjaafar, S., \& Elomri, A. (2013). The carbon-constrained EOQ. Operations Research Letters, 41(2), 172-179.

Ertogral, K., Darwish, M., \& Ben-Daya, M. (2007). Production and shipment lot sizing in a vendorbuyer supply chain with transportation cost. European Journal of Operational Research, 176(3), 1592-1606.

Goyal, S. K. (1977). An integrated inventory model for a single supplier-single customer problem. The International Journal of Production Research, 15(1), 107-111.

Goyal, S. K. (1988). A joint economic-lot-size model for purchaser and vendor: A comment. Decision sciences, 19(1), 236-241.

Goyal, S. K. (1995). A one-vendor multi-buyer integrated inventory model: A comment. European journal of operational research, 82(1), 209-210.

Gurtu, A., Jaber, M. Y., \& Searcy, C. (2015). Impact of fuel price and emissions on inventory policies. Applied Mathematical Modelling, 39(3), 1202-1216.

Hariga, M., \& Ben-Daya, M. (1999). Some stochastic inventory models with deterministic variable lead time. European Journal of Operational Research, 113(1), 42-51.

Helmrich, M. J. R., Jans, R., van den Heuvel, W., \& Wagelmans, A. P. (2015). The economic lot-sizing problem with an emission capacity constraint. European Journal of Operational Research, 241(1), 50-62.

Hill, R. M. (1997). The single-vendor single-buyer integrated production-inventory model with a generalised policy. European journal of operational research, 97(3), 493-499.

Hill, R. M. (1999). The optimal production and shipment policy for the single-vendor single-buyer integrated production-inventory problem. International Journal of Production Research, 37(11), 2463-2475.

Hoen, K. M. R., Tan, T., Fransoo, J. C., \& van Houtum, G. J. (2014). Effect of carbon emission regulations on transport mode selection under stochastic demand. Flexible Services and Manufacturing Journal, 26(1-2), 170-195.

Hua, G., Cheng, T. C. E., \& Wang, S. (2011). Managing carbon footprints in inventory management. International Journal of Production Economics, 132(2), 178-185. 
Jaber, M. Y., Glock, C. H., \& El Saadany, A. M. (2013). Supply chain coordination with emissions reduction incentives. International Journal of Production Research, 51(1), 69-82.

Jauhari, W. A., Pujawan, I. N., Wiratno, S. E., \& Priyandari, Y. (2011). Integrated inventory model for single vendor-single buyer with probabilistic demand. International Journal of Operational Research, 11(2), 160-178.

Kim, T., \& Goyal, S. K. (2009). A consolidated delivery policy of multiple suppliers for a single buyer. International Journal of Procurement Management, 2(3), 267-287.

Langley, C. J. (1980). The inclusion of transportation costs in inventory models: some considerations. Journal of Business Logistic, 2, 106-125.

Leuveano, R. A. C., Jafar, F. A. B., \& Muhamad, M. R. B. (2014a). Incorporating Transportation Costs Into Integrated Inventory Model for Single Supplier and Single Purchaser. Advanced Science Letters, 20(1), 290-293.

Leuveano, R. A. C., Jafar, F. A. B., Saleh, C., Muhamad, M. R. B., \& Rahman, M. N. A. (2014b). Incorporating Transportation Cost into Joint Economic Lot Size For Single Vendor-Buyer. Journal of Software, 9(5), 1313-1323.

Liao, C. J., \& Shyu, C. H. (1991). An analytical determination of lead time with normal demand. International Journal of Operations \& Production Management, 11(9), 72-78.

Lippman, S. A. (1971). Economic order quantities and multiple set-up costs. Management Science, 18(1), 39-47.

Lu, L. (1995). A one-vendor multi-buyer integrated inventory model. European Journal of Operational Research, 81(2), 312-323.

Mendoza, A., \& Ventura, J. A. (2008). Incorporating quantity discounts to the EOQ model with transportation costs. International Journal of Production Economics, 113(2), 754-765.

Montgomery, D. C., Bazaraa, M. S., \& Keswani, A. K. (1973). Inventory models with a mixture of backorders and lost sales. Naval Research Logistics Quarterly, 20(2), 255-263.

Moon, I., \& Choi, S. (1998). A note on lead time and distributional assumptions in continuous review inventory models. Computers \& Operations Research, 25(11), 1007-1012.

Nie, L., Xu, X., \& Zhan, D. (2006). Incorporating transportation costs into JIT lot splitting decisions for coordinated supply chains. Journal of Advanced Manufacturing Systems, 5(01), 111-121.

Ouyang, L. Y., Wu, K. S., \& Ho, C. H. (2004). Integrated vendor-buyer cooperative models with stochastic demand in controllable lead time. International Journal of Production Economics, 92(3), 255-266.

Ouyang, L. Y., Yeh, N. C., \& Wu, K. S. (1996). Mixture inventory model with backorders and lost sales for variable lead time. Journal of the Operational Research Society, 47(6), 829-832.

Piecyk, M., Cullinane, S., \& Edwards, J. (2007). Assessing the external impacts of freight transport. in McKinnon, A.C., Browne, M. and Whiteing, A. (Eds), Green Logistics, 2nd ed., Kogan Page, London, 31-50.

Rieksts, B. Q., \& Ventura, J. A. (2008). Optimal inventory policies with two modes of freight transportation. European Journal of Operational Research, 186(2), 576-585.

Rieksts, B. Q., \& Ventura, J. A. (2010). Two-stage inventory models with a bi-modal transportation cost. Computers \& Operations Research, 37(1), 20-31.

Swenseth, S. R., \& Buffa, F. P. (1990). Just-in-time: some effects on the logistics function. The International Journal of Logistics Management, 1(2), 25-34.

Swenseth, S. R., \& Godfrey, M. R. (2002). Incorporating transportation costs into inventory replenishment decisions. International Journal of Production Economics, 77(2), 113-130. 
Viau, M. A., Trepanier, M., \& Baptiste, P. (2009). Integration of inventory and transportation decisions in decentralised supply chains. International Journal of Logistics Systems and Management, 5(3-4), 249-272.

Wahab, M. I. M., Mamun, S. M. H., \& Ongkunaruk, P. (2011). EOQ models for a coordinated two-level international supply chain considering imperfect items and environmental impact. International Journal of Production Economics, 134(1), 151-158.

$\mathrm{Xu}, \mathrm{X} .$, Zhang, W., He, P., \& Xu, X. (2017). Production and pricing problems in make-to-order supply chain with cap-and-trade regulation. Omega, 66, 248-257.

Yıldırmaz, C., Karabatı, S., \& Sayın, S. (2009). Pricing and lot-sizing decisions in a two-echelon system with transportation costs. OR spectrum, 31(3), 629-650.

Zanoni, S., Mazzoldi, L., \& Jaber, M. Y. (2014). Vendor-managed inventory with consignment stock agreement for single vendor-single buyer under the emission-trading scheme. International Journal of Production Research, 52(1), 20-31.

\section{Online references}

FedEx Corporation. (2016, November 18). FedEx Shipping Rates [Technical report]. Retrieved from http://www.fedex.com/us/shipping-rates/surcharges-and-fees.html.

GHG Protocol Organization. (2016, December 2). FAQ [Organization report]. Retrieved from http://www.ghgprotocol.org/calculation-tools/faq.

US Env. Protection Agency. (2016, December 7). Sources of Greenhouse Gas Emissions [Government report]. Retrieved from http://www.epa.gov/ghgemissions/sources-greenhouse-gas-emissions

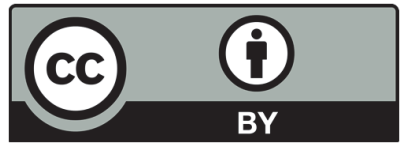

(C) 2017 by the authors; licensee Growing Science, Canada. This is an open access article distributed under the terms and conditions of the Creative Commons Attribution (CCBY) license (http://creativecommons.org/licenses/by/4.0/). 